\title{
Linking canopy reflectance to crop structure and photosynthesis to capture and interpret spatiotemporal dimensions of per-field photosynthetic productivity
}

\author{
Wei Xue $^{1}$, Seungtaek Jeong ${ }^{1}$, Jonghan Ko ${ }^{1}$, and John Tenhunen ${ }^{2}$ \\ ${ }^{1}$ Department of Applied Plant Science, Chonnam National University, 500757 Gwangju, South Korea \\ ${ }^{2}$ Department of Plant Ecology, BayCEER, University of Bayreuth, 95440 Bayreuth, Germany
}

Correspondence to: Wei Xue (xuewei8341@yeah.net) and Jonghan Ko (jonghan.ko@jnu.ac.kr)

Received: 14 November 2016 - Discussion started: 18 November 2016

Revised: 6 February 2017 - Accepted: 17 February 2017 - Published: 15 March 2017

\begin{abstract}
Nitrogen and water availability alter canopy structure and physiology, and thus crop growth, yielding large impacts on ecosystem-regulating/production provisions. However, to date, explicitly quantifying such impacts remains challenging partially due to lack of adequate methodology to capture spatial dimensions of ecosystem changes associated with nitrogen and water effects. A data fitting, where close-range remote-sensing measurements of vegetation indices derived from a handheld instrument and an unmanned aerial vehicle (UAV) system are linked to in situ leaf and canopy photosynthetic traits, was applied to capture and interpret inter- and intra-field variations in gross primary productivity (GPP) in lowland rice grown under flooded conditions (paddy rice, PD) subject to three nitrogen application rates and under rainfed conditions (RF) in an East Asian monsoon region of South Korea. Spatial variations (SVs) in both GPP and light use efficiency (LUE $\mathrm{Labs}_{\text {s }}$ ) early in the growing season were enlarged by nitrogen addition. The nutritional effects narrowed over time. A shift in planting culture from flooded to rainfed conditions strengthened SVs in GPP and LUE $\mathrm{Labs}_{\text {cabs }}$ Intervention of prolonged drought late in the growing season dramatically intensified SVs that were supposed to seasonally decrease. Nevertheless, nitrogen addition effects on SV of $\mathrm{LUE}_{\text {cabs }}$ at the early growth stage made PD fields exert greater SVs than RF fields. SVs of GPP across PD and RF rice fields were likely related to leaf area index (LAI) development less than to $\mathrm{LUE}_{\mathrm{cabs}}$, while numerical analysis suggested that considering strength in $\mathrm{LUE}_{\text {cabs }}$ and its spatial variation for the same crop type tends to be vital for better evaluation in landscape/regional patterns of
\end{abstract}

ecosystem photosynthetic productivity at critical phenology stages.

\section{Introduction}

Agricultural landscape in most Asia monsoon regions is featured by multicultural cropping systems comprising relatively small land holdings under 2 ha (Devendra, 2007). Changes in phenology of those crop ecosystems, where rice makes up a larger portion and exerts a rapid completion of the life cycle in a short period of time with marked changes in canopy dynamics, are of significant importance in regional controls of carbon balance and biogeochemical processes (Kwon et al., 2010; Lindner et al., 2015; Xue et al., 2017) and tend to be one of the drivers causing seasonal fluctuations of atmospheric $\mathrm{CO}_{2}$ concentration in the Northern Hemisphere (Forkel et al., 2016). To better understand their ecological implications under current climate and environmental changes, one of the main concerns lies in the spatiotemporal aspects of ecosystem photosynthetic productivity in the staple crop that is subject to different methods of field management and anthropogenic interventions, and underlying physiological mechanisms that are responsible for such spatiotemporal dimensions.

The stability, repeat measurement capability, and landscape to global coverage of remote sensing from satellites have triggered widespread use of such measurements to obtain spatial patterns of biophysical and biochemical variables in studies of land surface and atmospheric processes 
(Richardson et al., 2013). A recent study on flux modeling of agroecosystems introduced satellite products as input parameters (Adiku et al., 2006) and reported pixel-size dependency of prediction accuracy. A better prediction could be obtained if satellite products were applied at finer resolution. Accordingly, attempts made to assimilate the products into process-based crop growth models have been increasingly concerned (Tenhunen et al., 2009; Lee, 2014; Alton, 2017), due to resulting overestimations and/or under estimations in plant functional traits. Satellite images collected during plant growing seasons have been used to monitor crop growth and to predict yield production. However, their use has been limited by poor revisit times, coarse spatial resolution, and/or cloudy weather. They technically conceal delicate fluctuations of ecosystem productivity tightly associated with perfield ecological conditions on which plants survival and dispersal depend (Seo et al., 2014). Applications of spatially coarse satellite products generate considerable spatiotemporal uncertainties in evaluating strength of daily carbon fluxes among microsites of the same plant function type at principle growth stages. Multi-pragmatic solutions are suggested to develop spatial/temporal data fusions that integrate spatially hierarchical remote-sensing networks and in situ ground surface observations (Lausch et al., 2016; Pause et al., 2016), aiming to better monitor canopy dynamics and environmental impacts on them.

Of the various means that can aid the understanding of perfield ecological processes, the close-range remote-sensing technique is a realistically convenient measure that can provide timely temporal information of ecosystem dynamics at high spatial resolution. Recent applications in agronomy studies (Zhang and Kovacs, 2012; Ko et al., 2015; Jeong et al., 2016) have reinforced the feasibility of resolving the research gaps in terms of capturing spatiotemporal aspects of intra- and inter-field ecosystem photosynthetic productivity.

To best interpret spatiotemporal variations of ecosystem photosynthetic productivity captured by the close-range remote sensing, conventional physiological studies on canopy leaves remain essential (Sinclair and Horie, 1989; Niinemets and Tenhunen, 1997). As leaves are the small and basic units that constitute rice canopy volume, their functioning could change with canopy development and changing habitat conditions (Xue et al., 2016a, b), contributing to fluctuations in strength of seasonal canopy photosynthesis.

Traditional ecophysiology approaches are very limited in comparing neighboring plants and tend to neglect spatial dimensions. Landscape ecology can resolve ecosystem functioning at a broad scale but tends to be restricted to regional analysis at a higher hierarchical level beyond individual organisms. The central aims of this research are to construct a spatially integrative concept that assimilates quantitatively abundant data sets collected from a close-range remote-sensing system applied at field level and from traditional ecophysiology approaches at plot level, and to capture and interpret effects of different field management practices including nutrient application and water treatments on temporal and spatial aspects of ecosystem photosynthetic productivity according to their influences on canopy leaf physiology and structure.

The study evaluates two hypotheses. The first posits that the temporal course of canopy carbon gain capacity is driven primarily by leaf area index (LAI) development and solar radiation intensity at the reproductive stage (Xue et al., 2016a, 2017). Canopy leaf physiology is a primary factor that determines efficient use of canopy light use and therefore carbon gain capacity (Sinclair and Horie, 1989). Hence, spatial variability of ecosystem gross primary productivity (GPP) could be concurrently driven by canopy structure (i.e., LAI) and canopy leaf physiology (i.e., light use efficiency, $L E_{\text {cabs }}$ ). The second hypothesis posits that shifts of planting culture from flooded to rainfed (RF) conditions mean that water availability tends to be a primary factor determining ecosystem photosynthetic productivity. Growth of rainfed rice suffers from multiple uncertainties regarding timing/strength of precipitation and uptake of nutrient availability in soil (Kato et al., 2016). Significant changes in leaf and root anatomies, and canopy structure and function in rainfed rice could occur (Yoshida, 1981; Steudle, 2000). Greater variations in spatial aspects of ecosystem GPP, LAI, and LUE $\mathrm{E}_{\text {cabs }}$ in rainfed lowland rice than flooded rice are therefore anticipated.

\section{Materials and methods}

\subsection{Study site}

The field campaign was carried out at the agricultural field station of Chonnam National University, Gwangju, South Korea, which is located at $35^{\circ} 10^{\prime} \mathrm{N}, 126^{\circ} 53^{\prime} \mathrm{E}$, at an altitude of $33 \mathrm{~m}$ (Fig. 1). The mean annual air temperature and precipitation over past 2 decades averaged $13.8^{\circ} \mathrm{C}$ and $1400 \mathrm{~mm} \mathrm{yr}^{-1}$, respectively. The East Asian monsoon climate prevails from June to October in this region, during which time more than half of the annual precipitation occurs. The top layer of soil is categorized as loam with sand of $388 \mathrm{~g} \mathrm{~kg}^{-1}$, silt of $378 \mathrm{~g} \mathrm{~kg}^{-1}$, clay of $234 \mathrm{~g} \mathrm{~kg}^{-1}$, $\mathrm{pH}$ 5.5, organic carbon (C) content of $12.3 \mathrm{~g} \mathrm{~kg}^{-1}$, available phosphorus (P) of $13.1 \mathrm{~g} \mathrm{~kg}^{-1}$, and total nitrogen $(\mathrm{N})$ before fertilization of $1.0 \mathrm{~g} \mathrm{~kg}^{-1}$. Thirty-day-old seedlings of a new breeding line, Oryza sativa cv. Unkwang (Kim et al., 2006), were transplanted in flooded paddy rice (PD) fields on 20 May 2013 (day of year, DOY, 140). N, P, and potassium $(\mathrm{K})$ were mixed at a mass ratio of $11: 5: 6$ to generate fertilizer application rates of $0 \mathrm{~kg} \mathrm{Nha}^{-1}$ (no supplementary fertilizer, plot size $\sim 511 \mathrm{~m}^{2}$; low-nutrient group), $115 \mathrm{~kg} \mathrm{~N} \mathrm{ha}^{-1}$ (plot size $\sim 1387 \mathrm{~m}^{2}$; normal-nutrient group), and $180 \mathrm{~kg} \mathrm{Nha}^{-1}$ (plot size $\sim 511 \mathrm{~m}^{2}$; high-nutrient group) (Fig. 1). The nutrient treatment groups were isolated by $35 \mathrm{~cm}$ wide cement walls and inserted $1 \mathrm{~m}$ into the soil. $\mathrm{N}-$ based fertilizer was added to $80 \%$ of total $\mathrm{N}$ by hand spread- 
ing 2 days before transplanting. The remaining $20 \%$ was added at the active tillering phase of the vegetative stage. $\mathrm{P}$ based fertilizer was applied as $100 \%$ of the basal dosage. Kbased fertilizer was applied as $65 \%$ of the basal dosage, with the remaining $35 \%$ applied during the tillering phase. Seeds of the same rice cultivar were directly sown in an adjacent upland field that was being treated as RF rice $\left(\sim 64 \mathrm{~m}^{2}\right)$ on 22 April (DOY 112). The same fertilizer compound containing $115 \mathrm{~kg} \mathrm{~N} \mathrm{ha}^{-1}$ (PD normal-nutrient group) was applied to the RF Unkwang rice field twice, with $80 \%$ applied before seeding and the rest applied at the tillering phase. The RF field was not irrigated during the whole growing season. All field management practices conformed to local planting cultures. The life history of the Unkwang rice is generally aligned to a proposed classification of phenology in temperate rice (Yoshida, 1981), in which the rice spends about 30 days in the vegetative stage after transplanting, 30 days in the reproductive stage, and 30 days in the ripening period.

To better understand the physiological mechanisms that may contribute to the spatial patters of per-field photosynthetic productivity, a pair of experiments involving the PD and RF Unkwang rice in a controlled growth chamber at the University of Bayreuth $\left(11^{\circ} 34^{\prime} \mathrm{N}, 49^{\circ} 56^{\prime} \mathrm{E}\right)$ were conducted in September 2014. Thirty-day-old seedlings were transplanted into plastic containers with a top diameter of $25.4 \mathrm{~cm}$ and a height of $25 \mathrm{~cm}$ with similar plant spacing to the planting practice in the 2013 field experiment. The equivalent fertilizer containing $115 \mathrm{~kg} \mathrm{Nha}^{-1}$ was applied two times for both the PD and RF rice, before transplanting/sowing and at the tillering phase. All plants were then acclimated in the growth chamber to daytime air temperature of $30^{\circ} \mathrm{C}$, relative humidity of $60 \%$, night temperature of $25^{\circ} \mathrm{C}$, and light intensity of $900 \mu \mathrm{mol} \mathrm{m}^{-2} \mathrm{~s}^{-1}\left(35.64 \mathrm{MJ} \mathrm{m}^{-2} \mathrm{~d}^{-1}\right)$. Soil water content (SWC) in the RF rice containers was maintained between 0.2 and $0.4 \mathrm{~m}^{3} \mathrm{~m}^{-3}$ using soil moisture sensors (EC-5, Decagon, WA, USA).

\subsection{Field measurements of meteorological factors and SWC}

Meteorological factors including air temperature, relative humidity, wind speed, precipitation, and global radiation were continuously measured with a $2 \mathrm{~m}$ high WS-GP1 automatic weather station (AWS) installed at a margin of the RF field (Delta-T Devices Ltd., Cambridge, UK). Weather data were recorded every $5 \mathrm{~min}$, and were averaged and logged every $30 \mathrm{~min}$. Additionally, values of SWC at depths of 10, 30, and $60 \mathrm{~cm}$ at three sites in the RF field were continuously measured every $15 \mathrm{~min}$ using the soil moisture sensors. SWC data recorded by the sensors were calibrated by actual SWC measurements conducted in the laboratory with the same soil. SWC was then converted to soil water potential $\left(\psi_{s}\right)$ with standard soil water retention curves of Van Genuchten (1980) as modified by Xue et al. (2016b).

\subsection{Field measurements of diurnal courses of leaf and canopy carbon dioxide $\left(\mathrm{CO}_{2}\right)$ exchange}

Diurnal gas exchange and chlorophyll fluorescence measurements in fully expanded uppermost, second, third, and fourth leaves of canopy profiles for the PD high-nutrient group were conducted on day after transplanting (DAT) 57 and 73 (DOY 197 and 213, respectively) using a GFS-3000 portable gas exchange and PAM-Fluorometer 3050-F chlorophyll fluorescence system (Heinz Walz GmbH, Effeltrich, Germany) to track ambient environmental conditions external to the leaf cuvette. Repeated measurements of diurnal courses of leaf gas exchange were carried out in the uppermost leaves in the PD low-nutrient group on DOY 171, 172, 179, 180, and 199 (DAT 31, 32, 39, 40, and 59, respectively); in the PD normalnutrient group on DOY 175, 177, 195, and 211 (DAT 35, 37,55 , and 71, respectively); in the PD high-nutrient group on DOY 170 and 178 (DAT 30 and 38, respectively); and in the RF rice on DOY 157, 181, 201, 205, 222, 223, 227, 231,235 , and 238. The midportions of two or three leaves were enclosed in the leaf chamber from sunrise to sunset. The photosynthetic rate and momentary micrometeorological factors just above the plant canopies were recorded every $5 \mathrm{~min}$, and automatic calibration was done by a user-defined program every $15 \mathrm{~min}$. Leaf light use efficiency based on incident photosynthetically active radiation (PAR; $L E_{\text {leaf }}$ ) was estimated using photosynthesis data recorded at incident PAR $<200 \mu \mathrm{mol} \mathrm{m}^{-2} \mathrm{~s}^{-1}$.

The diurnal course of canopy gas exchange was conducted in a custom-built transparent chamber $(\mathrm{L} 39.5 \times \mathrm{W} 39.5 \times \mathrm{H} 50.5 \mathrm{~cm})$ used for net ecosystem gas exchange (NEE) measurement and in an opaque chamber $(\mathrm{L} 39.5 \times \mathrm{W} 39.5 \times \mathrm{H} 50.5 \mathrm{~cm})$ designed for ecosystem respiration $\left(R_{\text {eco }}\right)$ measurement (Lindner et al., 2016; Xue et al., 2016a) on $\sim$ DOY $159,167,175,200,220$, and 240. Measurements on DOY 240 were only available at the PD normal-nutrient group and RF rice. Four white frames, with three filled with healthy plants and one set on bare soil without any plants, were randomly deployed in each PD nutrient group and in the RF field (Lindner et al., 2016). They were inserted into the soil at a depth of $10 \mathrm{~cm}$ before transplanting/sowing to block air leak at the interface between the frame and soil surface, and kept in the fields until plants were harvested. Diurnal courses of NEE and $R_{\text {eco }}$ per square meter were monitored each hour from sunrise to sunset. Differences of air temperature between the inside and outside of the chamber were controlled to $<1^{\circ} \mathrm{C}$ using ice packs positioned at the back side of the chamber to avoid shadow effects of the ice packs. Incident PAR inside the transparent chamber was measured with a LI-190 quantum sensor (LI-COR, Lincoln, NB, USA). GPP estimation was derived using the equation

$\mathrm{GPP}=-\mathrm{NEE}+R_{\mathrm{eco}}$, 


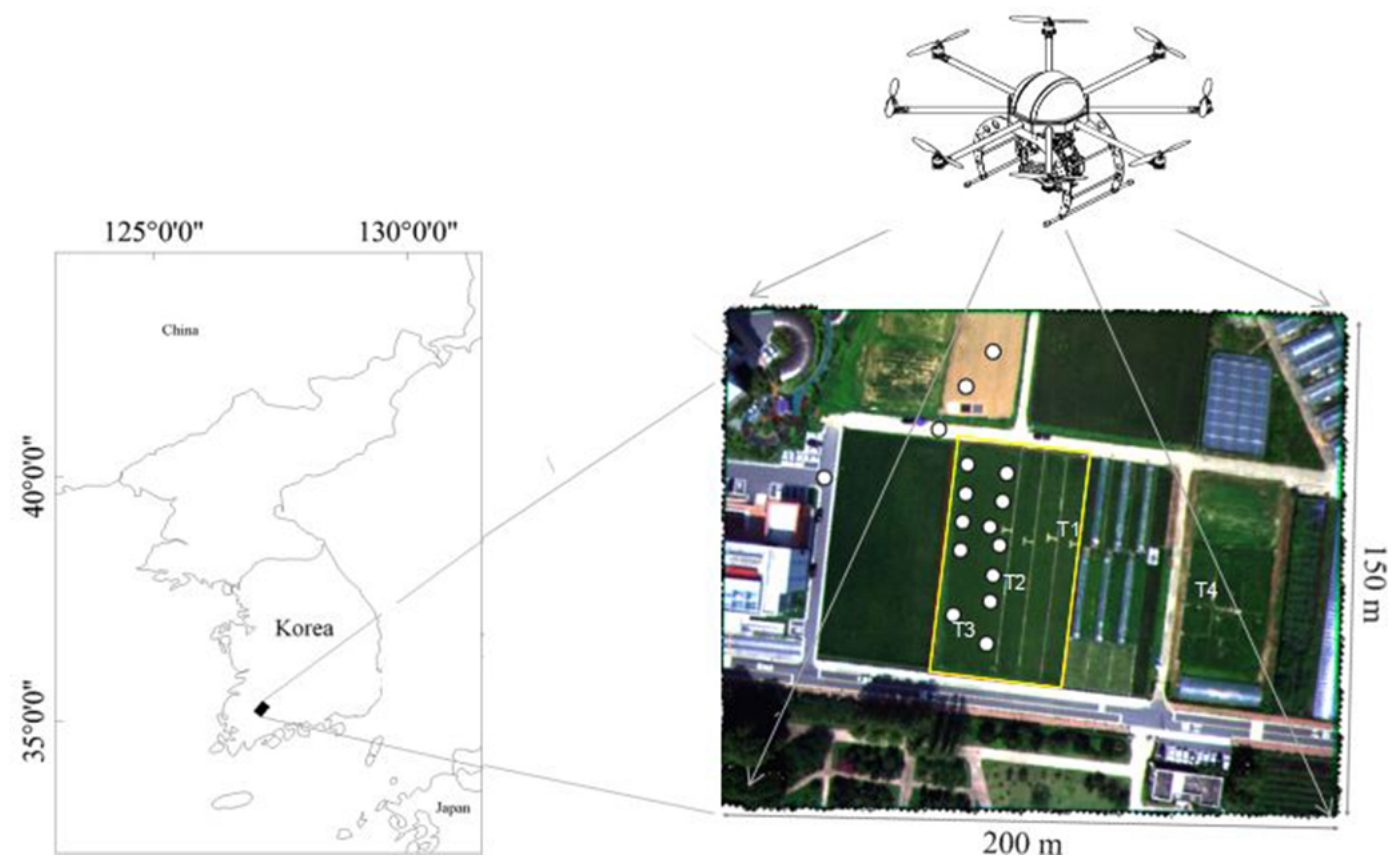

Figure 1. Illustration of the Gwangju study site where field data collection was carried out. Yellow square and white circles represent sites of paddy fields and those marked for measurements of ground reflectance by one handheld miltispectral radiometer (MSR) to validate UAV imagery. T1: PD rice under low-nutrient conditions (no supplementary nitrogen applied); T2: PD rice under high-nutrient conditions (180 kg $\left.\mathrm{N} \mathrm{ha}^{-1}\right)$; T3: PD rice under normal-nutrient conditions $\left(115 \mathrm{~kg} \mathrm{Nha}^{-1}\right)$; and T4: RF rice (115 $\left.\mathrm{kg} \mathrm{Nha}^{-1}\right)$. PD: paddy; RF: rainfed.

where $R_{\text {eco }}$ rates at times when NEE rates were measured were determined from an exponential regression with respect to chamber air temperature ( $\left.T_{\text {air }}\right)$ (Xue et al., 2016a). A classical hyperbolic light response function (Eq. 5; see below) was fit to estimate GPP (sum of NEE and $R_{\text {eco }}$ ), yielding canopy light use efficiency (LUE $\mathrm{Lint}_{\text {t }}$ ), defined as the initial slope of the response, and an estimate of maximum GPP rate $\left(\mathrm{GPP}_{\max }\right)$ at a relatively high PAR level (Lindner et al., 2016).

\subsection{Field measurements of canopy reflectance}

In situ reflectance measurements were carried out with a model MSR4 handheld multispectral radiometer with four spectral bands (CROPSCAN Inc., Rochester, MN, USA). Incident radiation was measured with a view angle of $180^{\circ}$, and that reflected by rice canopies was measured with a view angle of $28^{\circ}$. Weekly reflectance measurements conducted around plants sampled for canopy gas exchange were repeated six times in each PD nutrient treatment and three times in the RF field at solar noon midday, when the sky was clear without clouds. The normalized difference vegetation index (NDVI) was a product of differences of reflectance in the field of red (the central bandwidth of $660.9 \mathrm{~nm}$ ) and near infrared (the central bandwidth of $813.2 \mathrm{~nm}$ ). Estimations of ground-based NDVI were made on the days of canopy gas exchange measurements (Xue et al., 2016a).
Spectral reflectance at fine spatial resolution $\approx 10 \mathrm{~cm}$ for the whole PD field and RF field was measured on 21 June (DOY 172, vegetative stage), 11 July (DOY 192, early reproductive stage), 25 July (DOY 206, middle reproductive stage), 8 August (DOY 220, early ripening stage), and $21 \mathrm{Au}-$ gust (DOY 233, middle ripening stage) using an unmanned aerial vehicle (UAV) system (details of the construction of the UAV system are given in Jeong et al., 2016). The UAV images were acquired at approximately local noon $\pm 30 \mathrm{~min}$ (i.e., KST $12: 10$ to $13: 10$ ), when there were clear skies or homogenous cloudy skies. The camera exposure was set at its minimum value $\left(0.5 \mu \mathrm{m} \mathrm{s}^{-1}\right)$ under clear-sky conditions and ranged between 1.0 to $2.0 \mu \mathrm{m} \mathrm{s}^{-1}$ under homogenous cloudy skies to obtain the best images. When recording UAV images, the mini-MCA6 multispectral camera (Tetracam Inc., Chatsworth, CA, USA) loaded on board the UAV - which detected ground reflectance with the wavelength bands of 450 , $550,650,800,830$, and $880 \mathrm{~nm}$ - was always positioned vertically to the ground.

Pseudo-invariant targets (PITs) at three different colors (white, black, and gray) were placed adjacent to the PD field prior to each UAV flight. At-surface reflectance values of two selected wavebands at 800 and $650 \mathrm{~nm}$ from those PITs were obtained using the other handheld spectrometer (MSR16 with 16 wave bands; CROPSCAN). Linear regression correlations were made between mini-MCA6 digital values and the reflectance from the MSR16 at each corresponding waveband, with a correlation coefficient rang- 

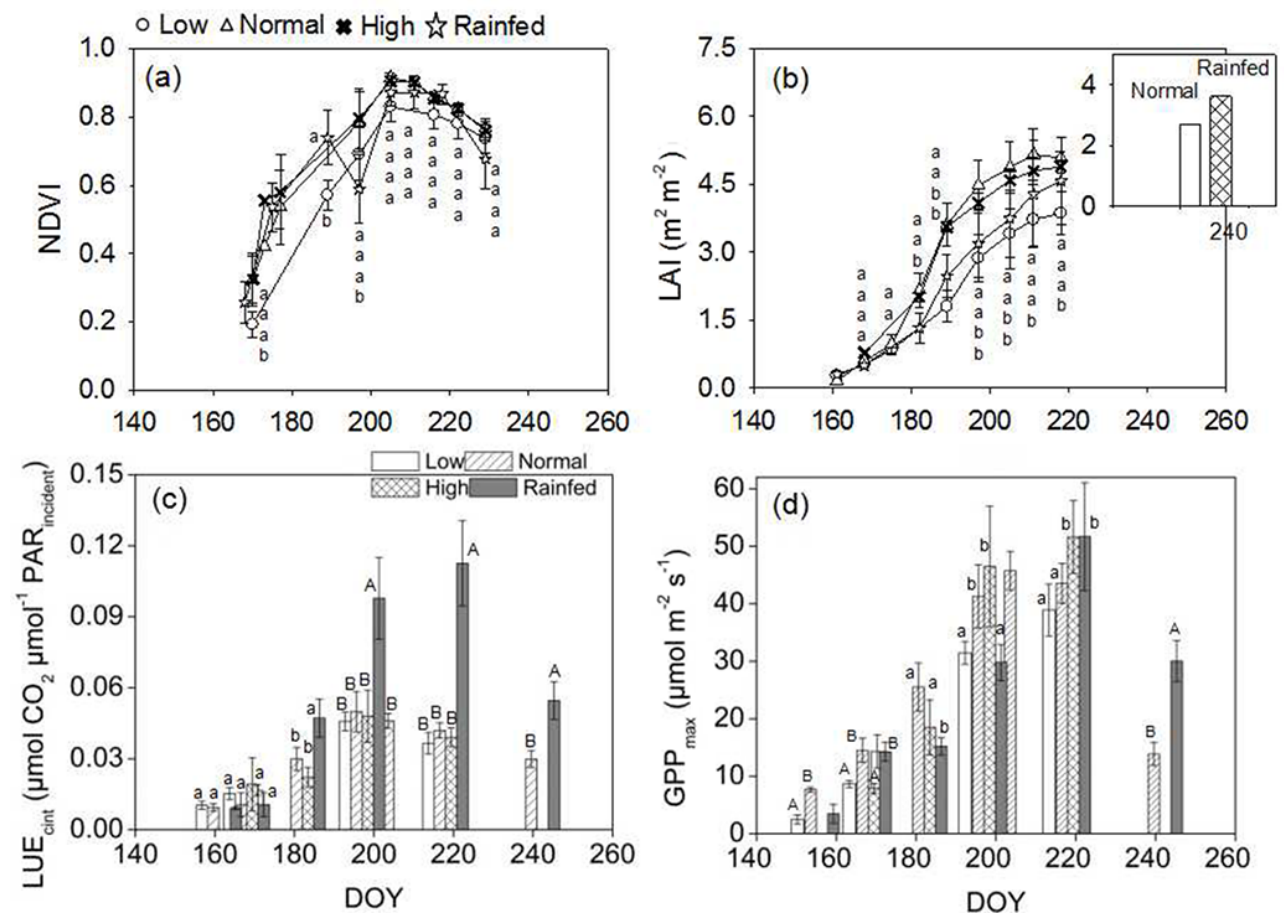

Figure 2. Seasonal courses of (a) normalized difference vegetation index (NDVI), (b) leaf area index (LAI), (c) canopy light use efficiency based on incident PAR ( $\left.\mathrm{LUE}_{\text {cint }}\right)$, and (d) maximum gross primary production $\left(\mathrm{GPP}_{\max }\right)$ measured at plot level in the PD low-, normal-, and high- nutrient groups, and in the RF rice. Statistic analysis showed significance at the 0.05 level (small letters) and at the 0.01 level (capital letters). Mean $\pm \mathrm{SD}, n=3$ to 6 . DOY: day of year. PD: paddy; RF: rainfed.

ing from 0.98 to 0.99 (detailed descriptions are provided in Ko et al., 2015; Jeong et al., 2016). Camera measurements were then calibrated based on at-surface measurements by applying each linear regression to the field imagery. Evaluation of the radiometrically corrected UAV images was carried out by comparisons with measurements of 16 ground point reflectance values, which comprised 12 points in paddy fields and 4 points in bright cement, dark asphalt, bare soil, and tilled soil. There were close correspondences between reflectance derived from the radiometrically corrected UAV images and those measured at the ground over all UAV flight dates, with correction efficiency $(E)$ up to 0.99 and root mean square error (RMSE) ranging between 0.01 and 0.05 (Appendix Fig. A1). Radiometrically calibrated reflectance at red, green, and blue bands $(450,550$, and $650 \mathrm{~nm}$, respectively) on 21 June/DOY 172 (clear sky), when low-density vegetation canopies with large exposure of water surface were consistently lower than at-surface measurements (Fig. A1a), resulting in risks of overestimating the field NDVI (a product of differences in reflectance of the red $(650 \mathrm{~nm})$ and near infrared $(800 \mathrm{~nm}))$ and therefore biased estimation of $\mathrm{GPP}_{\text {day }}$ and $\mathrm{LUE}_{\text {cabs. }}$. For the sake of brevity the radiometrically calibrated camera reflectance of red waveband on 21 June/DOY 172 were recalibrated by a linear regression line against at-surface measurements (Fig. A1a; $\left.\rho_{\text {red ground meas }}=1.761 \times \rho_{\text {red_UAV }}, R^{2}=0.76, p<0.01\right)$.

\subsection{Measurements of leaf area, $\mathrm{N}$ content, and leaf water potential}

After conducting leaf and canopy gas exchange measurements, leaf samples were collected to estimate leaf area and $\mathrm{N}$ content. Three bundles consisting of 15 plants from each treatment were harvested on DAT 26, 33, 54, 72, and 86, and total plant area (leaf and stem) was determined with a LI3100 leaf area meter (LI-COR, Lincoln, Nebraska, USA). Leaves of the PD and RF rice grown in the growth chamber were harvested on DAT 33 and 55. All plant materials were dried at $\sim 60^{\circ} \mathrm{C}$ for at least 2 days before measurements of leaf nitrogen content. Leaf nitrogen content was quantified using a $\mathrm{C}: \mathrm{N}$ analyzer (Model 1500, Carlo Erba Instruments, Milan, Italy). Weekly measurements of LAI were conducted before DOY 220 using a LI-2000 portable plant canopy analyzer (LI-COR) at the same locations where atsurface canopy reflectance values were sampled using the CROPSCAN. These were calibrated using those obtained by the harvest method. LAI measurements on DOY 240 were supplemented referring to Lindner et al. (2016). At the same measuring times as leaf gas exchange was conducted in $\mathrm{Au}-$ gust, daily courses of leaf water potential in the RF rice were collected with a pressure chamber (PMS Instruments, Corvallis, OR, USA). Healthy and well-expanded leaves in plant 
canopies were enclosed in a plastic bag before cutting and rapidly transferred into a pressure chamber.

\subsection{Data assimilation}

Assessment of influences of field management practices (i.e., nutrient and water availability) in crop photosynthetic traits and interpretation of the presence of such spatiotemporal fluctuations require development of a data assimilation process capable of linking in situ observations of leaf and canopy photosynthetic traits and vegetation information at field level. Here, a simple concept model aiming to resolve the objective stated above was developed, up-scaling application of the classical light response model of leaf photosynthesis to canopy and field dimensions using hyperspectral reflectance of ground surface collected at corresponding scales in Eqs. (2-8):

$$
\begin{aligned}
\mathrm{LUE}_{\mathrm{cint}} & =a_{1} \times \mathrm{LAI}+b_{1} \\
\mathrm{GPP}_{\text {max }} & =a_{2} \times \mathrm{LAI}+b_{2}, \\
\mathrm{LAI} & =a_{3} \times \mathrm{NDVI}^{2}+b_{3} \times \mathrm{NDVI}+c_{3} \\
\mathrm{GPP}_{\text {day }} & =\sum_{j=1}^{N} \frac{\mathrm{LUE}_{\mathrm{cint}} \times \mathrm{GPP}_{\max } \times \mathrm{PAR}_{j}}{\mathrm{LUE}_{\mathrm{cint}} \times \mathrm{PAR}_{j}+\mathrm{GPP}_{\text {max }}} \\
\mathrm{fAPAR} & =\mathrm{fAPAR}_{\text {max }}\left[1-\left(\frac{\mathrm{NDVI}_{\text {max }}-\mathrm{NDVI}}{\mathrm{NDVI}_{\text {max }}-\mathrm{NDVI}_{\text {min }}}\right)^{\varepsilon}\right]
\end{aligned}
$$

$$
\begin{aligned}
\mathrm{fAPAR} & =a_{4} \times \mathrm{NDVI}+b_{4}, \\
\mathrm{LUE}_{\text {cabs }} & =\frac{\mathrm{GPP}_{\text {day }}}{\mathrm{fAPAR} \times \mathrm{PAR}_{\text {day }}},
\end{aligned}
$$

where, in Eq. (2), $a_{1}$ and $b_{1}$ are regression coefficients for the LUE $_{\text {cint }}-$ LAI correlation based on plot measurements (Table 1). In Eq. (3), $a_{2}$ and $b_{2}$ are regression coefficients for the GPP $_{\max }$-LAI correlation based on plot measurements (Table 1), consistent with previous reports (Lindner et al., 2015, 2016). In Eq. (4), $a_{3}, b_{3}$, and $c_{3}$ are regression coefficients for the LAI-NDVI mathematic correlation across all data sets based on plot measurements (Table 1), which is consistent with a 3-year report in rice in terms of LAI-NDVI trajectory by Jo et al. (2015). In Eq. (5) GPP day is daily integrated GPP per pixel, a product of light use efficiency based on incident PAR (LUE cint $_{\text {) }}$, GPP ${ }_{\text {max }}$, and half-hourly averaged $\mathrm{PAR}_{j}$ obtained from the AWS. $N$ is the number of observations of incident PAR during daytime. In Eq. (6), fAPAR max $_{\text {ax }}$ is the maximum fraction of absorbed photosynthetically active radiation, $\mathrm{NDVI}_{\max }$ is the maximum NDVI of the fAPAR-NDVI relationship, $\mathrm{NDVI}_{\min }$ is the minimum NDVI, and $\varepsilon$ is a coefficient for green crop canopies, referring to Table 1 and Xue et al. (2016a). $a_{4}$ and $b_{4}$ in Eq. (7) are regression coefficients for the fAPAR-NDVI correlation in senescing canopies (Table 1 , referring to the stage after the middle ripening stage in rice), derived from Inoue et al. (2008). Light use efficiency based on daily canopy light interception per pixel (LUE $\left.\mathrm{Labs}_{\mathrm{c}}\right)$ in Eq. (8) is a product of $\mathrm{GPP}_{\text {day }}$, fAPAR, and PAR day (daily integrated incident PAR).

\subsection{Geospatial statistic}

Regionalized variable theory takes the differences between pairs of values separated by a certain quantity, usually distance, commonly expressed as variance (Vieira et al., 1983). A widely used geostatistical analysis to depict the spatial correlation structure of observations in space such as field soil fertility and temperature as well as other ecological processes is semi-variogram (Pierson and Wight, 1991; Loescher et al., 2014), given by

$$
\begin{aligned}
\gamma(h) & =\frac{1}{2 \mathrm{~N}(h)} \sum_{j=1}^{\mathrm{N}(h)}\left[z\left(x_{j}\right)-z\left(x_{j}+h\right)\right]^{2}, \\
\mathrm{CV}_{\text {sill }} & =\frac{\sqrt{2 \times \gamma_{\text {sill }}}}{\text { Mean }},
\end{aligned}
$$

where $z\left(x_{j}\right), j=1,2, \ldots, n$ denotes the set of $\mathrm{GPP}_{\text {day }} / \mathrm{LUE}_{\text {cabs }}$ data; $x_{j}$ is the vector of spatial coordinates of the $j$ th observation; $h$ is the pixel distance of sample values (lag); $\mathrm{N}(h)$ is the number of pairs of values separated by lag; and $\gamma(h)$ is semi-variance for the lag. $\mathbf{C V}_{\text {sill }}$ is a coefficient of variance using the sill and value of the mean for estimation. The semi-variogram simply describes how the variance of observations changes with the distance in a given direction, or it is averaged over all directions. The averaged semi-variance over all directions used in this research looked for an overall pattern between proximity and the similarity of pixel values, providing a single value that describes the spatial autocorrelation of the data set as a whole. Most often, semi-variance values increase until they reach a maximum approximately equal to the sample variance of the measured variable known as the "sill". The lag at which the sill is reached is known as the "range". Beyond the range, values of observations are no longer spatially correlated. Sill values refract magnitude of spatial variability of variables in the field. Several simple functions are commonly used to model semivariogram, which must be proven to be definitely positive. An exponential rise to the maximum function for approximating a spherical model was used to extrapolate the value of the sill, listed below:

$\gamma(h)=a \times(1-\exp (-b \times h))$,

where $b$ is the sill and $a$ is the nugget value.

\subsection{Statistical analysis}

Descriptive statistics of the data-included computation of the sample mean, maximum (max), and coefficient of variation $\left(\mathrm{CV}_{\text {traditional }}\right)$. A nonlinear least-squares method for GPP/PAR curves was executed using R software (R 3.2.3, $\mathrm{R}$ Development Core Team, Austria). The data fitting that 
Table 1. Values of coefficients for Eqs. (2-7).

\begin{tabular}{lrrrrrrrr}
\hline Eqs. & Coef. & Values & Coef. & Values & Coef. & Values & Coef. & Values \\
\hline Eq. (2) & $a_{1}$ PD & 0.0074 & $b_{1} \_$PD & 0.0107 & & & & \\
& $a_{1} \_$RF & 0.0211 & $b_{1}$ RF & 0.0070 & & & & \\
Eq. (3) & $a_{2}$ & 8.571 & $b_{2}$ & 4.081 & & & & \\
Eq. (4) & $a_{3}$ & 7.398 & $b_{3}$ & -1.752 & $c_{3}$ & 0.452 & & \\
Eq. (6) & $f$ APAR $_{\max }$ & 0.95 & $\mathrm{NDVI}_{\max }$ & 0.94 & NDVI $_{\text {min }}$ & 0.11 & $\varepsilon$ & 0.6 \\
Eq. (7) & $a_{4}$ & 0.169 & $b_{4}$ & 0.765 & & & & \\
\hline
\end{tabular}

* Values of coefficients for Eq. (7) were derived from Inoue et al. (2008). PD: paddy rice; RF: rainfed rice.

links remote-sensing data and ecophysiological measurements and geostatistical analyses were processed using IDL 8.0/ENVI 4.8 software (EXELIS Inc., Rochester, NY, USA).

\section{Results}

\subsection{Seasonal courses of at-surface NDVI, LAI, LUE $_{\text {cint }}$, and GPP $_{\max }$}

Analysis of variance (ANOVA) for NDVI indicated that NDVI values measured around DOY 170 between the PD normal- and high-nutrient groups were analogous but significantly higher than the low-nutrient group at the 0.05 level (Fig. 2a; $p=0.026$ ). There was not a statistical difference at the 0.05 significance level between the RF and PD lownutrient group. No significant discrepancy existed between the PD normal- and high-nutrient groups over the growing season $(p>0.1)$. Higher NDVI at the PD fertilizer addition groups was evident during the vegetative stage and early in the reproductive stage before DOY $200(p=0.06)$. Such a clear discrepancy in NDVI between the PD low-nutrient and fertilization groups and the RF rice was not evident after DOY $210(p=0.10)$. NDVI values advanced to decline after plants in the PD field arrived at maximum levels around DOY 210. However, the RF rice remained green around DOY 240 with approximately $23 \%$ higher LAI when plants in the PD field started senescence (Fig. 2b), which resulted in a relatively higher at-surface NDVI that was captured also by field images of NDVI derived from the UAV system. LAI in the PD normal-nutrient group was similar to those of the high-nutrient group at the corresponding growth stages (Fig. 2b), consistent with a seasonal course of NDVI for the normal/high-nutrient groups. Enhanced LAI development with addition of fertilizer was evident after DOY 180 (Fig. 2b; $p<0.05$ ), and N-related effects persisted until around DOY 210, consistent with NDVI development among PD nutrient groups. LAI in the RF rice ranged between the PD low-nutrient and fertilization groups, while it remained higher on DOY 240. Regression analysis for the NDVI-LAI relationship in grouped data sets showed a common trajectory across the PD nutrient groups and RF rice (Fig. 3a; $R^{2}=0.95, p<0.001$ ).
A curvilinear response of the GPP rate to incident PAR fit well with the classical light response model at each measuring date (data not shown), as previously reported (Eq. 5; Lindner et al., 2016). The resulting LUE cint $_{\text {on DOY } 160 \text { was }}$ approximately $0.01 \mu \mathrm{mol} \mathrm{CO}_{2} \mu \mathrm{mol}^{-1}$ PAR $_{\text {incident }}$, crossing the PD nutrient groups and the RF rice, and rapidly increased after DOY 180 (Fig. 2c). Differences in LUE ${ }_{\text {cint }}$ among the PD nutrient groups were relatively small $(<20 \%)$ on the corresponding dates. Nevertheless, the RF rice presented dramatically high $\mathrm{LUE}_{\text {cint }}$ as compared to the PD rice from DOY 180 to the end of the growing season, showing the highest values at 0.11 and $0.05 \mu \mathrm{mol} \mathrm{CO} \mu_{2} \mathrm{~mol}^{-1}$ in the RF and $\mathrm{PD}$ rice, respectively. Generally speaking, PD rice in the fertilization groups had dramatically higher $\mathrm{GPP}_{\max }$, with a maximum level of $51.60 \mu \mathrm{mol} \mathrm{CO}_{2} \mathrm{~m}^{-2} \mathrm{~s}^{-1}$ compared to $38.90 \mu \mathrm{mol} \mathrm{CO} \mathrm{Cm}^{-2} \mathrm{~s}^{-1}$ of the low-nutrient group (Fig. 2d). Maximum GPP max $_{\text {in }}$ the RF rice was analogous to that of the PD rice and remained higher on DOY $240(p<0.01)$, which was ascribed to green LAI (Fig. 2b). Similarities in photosynthetic traits in terms of NDVI, LAI, GPP ${ }_{\max }$, and $\mathrm{LUE}_{\text {cint }}$ between the normal- and high-nutrient groups at the corresponding growth stages were evident. Hence, comparisons in those parameters stated below referred to the PD low- and normal-nutrient groups.

Relatively low LAI in the RF rice during the reproductive stage but higher $\mathrm{LUE}_{\text {cint }}$ than the PD at the same growing stage resulted in a distinction regarding the LAI-LUE $\mathrm{E}_{\text {cint }}$ correlation associated with slope (Fig. $3 \mathrm{c} ; R^{2}=0.74, p=$ 0.02 in RF, $R^{2}=0.85, p<0.0001$ in PD; $F=22.16, p=$ $1.398 e-05$; see Table 1). A common linear regression for the LAI-GPP ${ }_{\max }$ correlation that interpreted approximately $88 \%$ of variations in $\mathrm{GPP}_{\max }$ across the PD nutrient groups and $\mathrm{RF}$ rice was evident (Fig. $3 \mathrm{~b} ; R^{2}=0.88, p<0.0001$ ). Canopy leaf nitrogen content $\left(\mathrm{N}_{\mathrm{m}}, \%\right)$ collected in the field and controlled growth chamber was significantly higher in the RF rice after DOY 180 (Fig. 4a, b; $p<0.05$ ). Light use efficiency at leaf level ( $\mathrm{LUE}_{\text {leaf }}$ ) was positively correlated with $\mathrm{N}_{\mathrm{m}}$ (Fig. $4 \mathrm{~b} ; R^{2}=0.65, p=0.0007$ ). This implied that the improved $\mathrm{LUE}_{\text {cint }}$ in the RF rice observed after DOY 180 could be related to strengthened capacity of $\mathrm{N}$ accumulation in canopy leaves. 

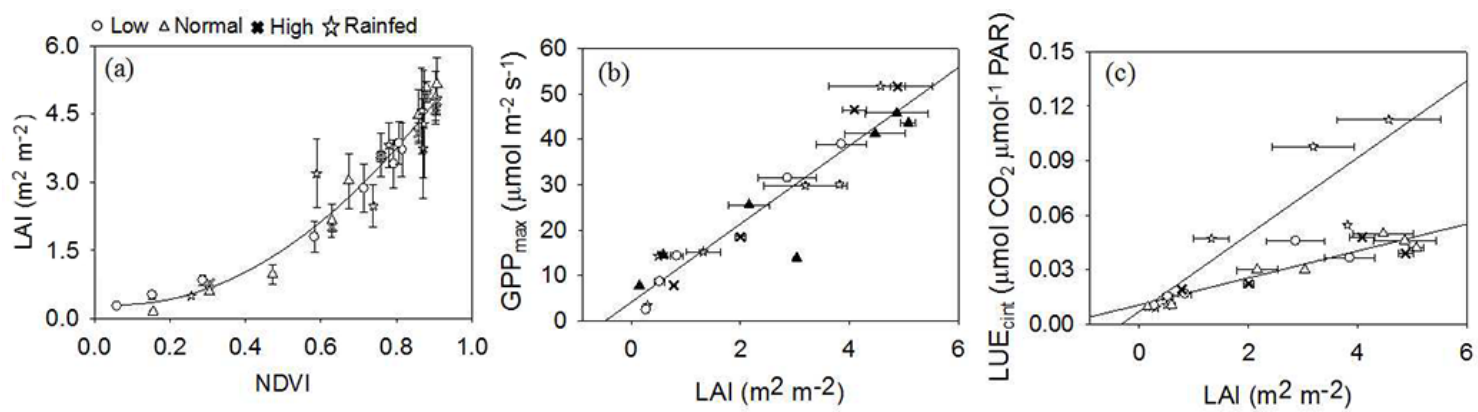

Figure 3. Correlations between (a) normalized difference vegetation index (NDVI) and LAI, (b) GPP max and LAI, and (c) canopy light use efficiency ( $\mathrm{LUE}_{\text {cint }}$ ) and LAI across the PD low-, normal-, and high-nutrient groups, and in the RF rice. Mean $\pm \mathrm{SD}, n=3$ to 6 . PD: paddy; RF: rainfed.
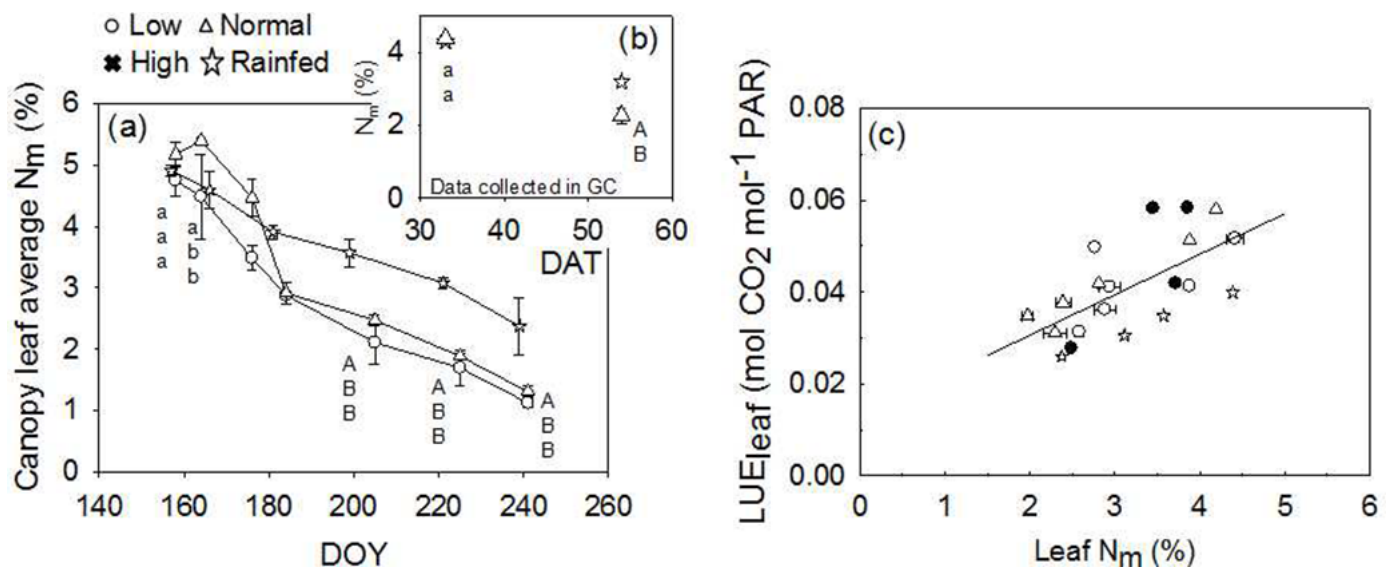

Figure 4. Seasonal courses of leaf nitrogen content $\left(\mathrm{N}_{\mathrm{m}}\right)$ in (a) the PD low-, normal-, and high-nutrient groups, and in the RF rice in the

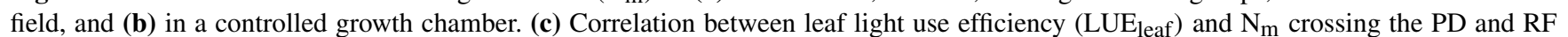
rice. Mean $\pm \mathrm{SD}, n=3$ to 6 . Statistic analysis showed significance at the 0.05 level (small letters) and at the 0.01 level (capital letters). DOY: day of year; DAT: day after transplanting; PD: paddy; RF: rainfed; GC: growth chamber.

\subsection{Field mapping of GPP $_{\text {day }}$ and $\mathrm{LUE}_{\text {cabs }}$}

Field maps of $\mathrm{GPP}_{\text {day }}$ and $\mathrm{LUE}_{\text {cabs }}$ at principle growth stages (Figs. 5 and 6) clearly showed that seasonal change of withinfield $\mathrm{GPP}_{\text {day }}$ at each nutrient group could be quantitatively mapped using three colors (yellow, blue, and red) corresponding to low, medium, and high numerical values (respectively). Pink pixels and bright red pixels were respectively observed in the PD and RF rice on measuring date 8 August (DOY 220), during which time most rice plants proceeded to ripen, showing the highest LAI. However, color distribution in space at a specific growth stage within nutrient groups, especially in the normal- and low-nutrient groups on 11 July (DOY 192) and 21 August (DOY 223), seemed to be uneven (Fig. 5b, d). Furthermore, uneven distribution in the RF rice was intensified as compared with the PD rice on the corresponding dates. For $\mathrm{LUE}_{\mathrm{cabs}}$, appearance of greater spatial variability in color distribution was seen at the early growth stage in both PD and RF rice (Fig. 6a, e), which seemed to contrast with spatial aspects of GPP day over the growing season. $\mathrm{LUE}_{\mathrm{cabs}}$ distributions in space over the reproductive stage (11 July, DOY 192) tended to approach homogeneity in either PD nutrient groups or RF rice (Fig. 6b, c, f, g).

Descriptive statistics including mean, max, and $\mathrm{CV}_{\text {traditional }}$ in $\mathrm{GPP}_{\text {day }}$ and $\mathrm{LUE}_{\text {cabs }}$ respectively described their mean, their maximum values at field scale, and within-field variation of mean across the growing season (Table 2). Max GPP day differed significantly between the normal- $\left(7.29 \mathrm{~g} \mathrm{C} \mathrm{m}^{-2} \mathrm{~d}^{-1}\right)$ and low-nutrient $(3.78 \mathrm{~g}$ $\mathrm{C} \mathrm{m}^{-2} \mathrm{~d}^{-1}$ ) groups 4 weeks after transplantation, which was clearly apparent in the visual display of pixel $\mathrm{GPP}_{\text {day }}$ as well (Fig. 5a, d). Nevertheless, field mean values among the three nutrient groups were close to one another. The enhanced field mean of $\mathrm{GPP}_{\text {day }}$ in the normal-nutrient group by approximately $36 \%$ compared to the low-nutrient group appeared on 11 June (DOY 192). Such a large discrepancy persisted until the end of the growing season. Except for the early growth stage, the three nutrient groups showed similar values in the maximum GPP $_{\text {day }}$, which reached $12.49 \mathrm{~g} \mathrm{C} \mathrm{m}^{-2} \mathrm{~d}^{-1}$ for the normal-nutrient group around 


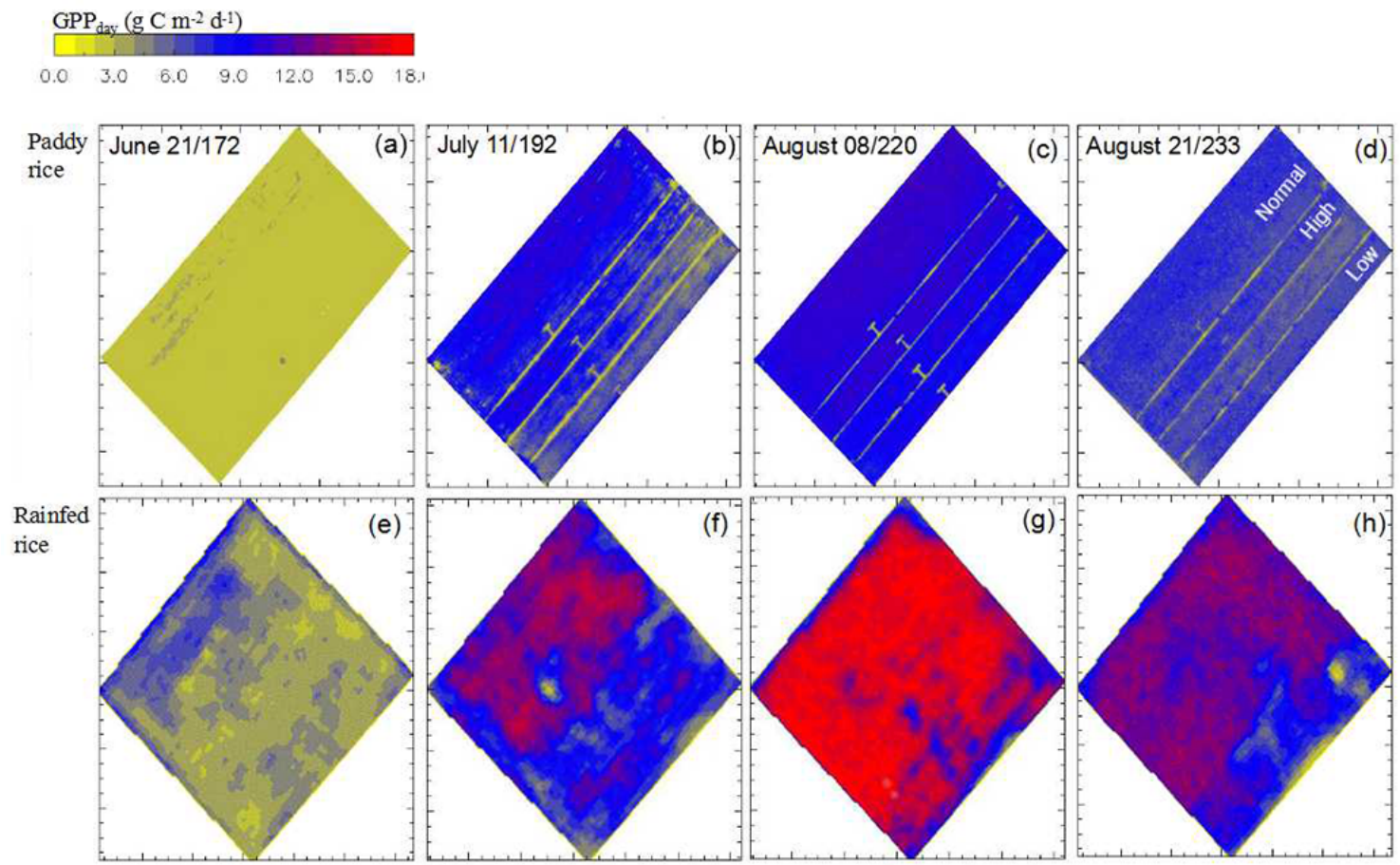

Figure 5. Field mapping of daily integrated gross primary productivity $\left(\mathrm{GPP}_{\text {day }}\right)$ in the PD rice and RF rice at principle growth stages: vegetative stage (21 June/DOY 172), middle reproductive stage (11 July/DOY 192), early ripening stage (8 August/DOY 220), and middle ripening stage (21 August/DOY 233). Date are expressed as MM DD/DOY. DOY: day of year; PD: paddy; RF: rainfed.

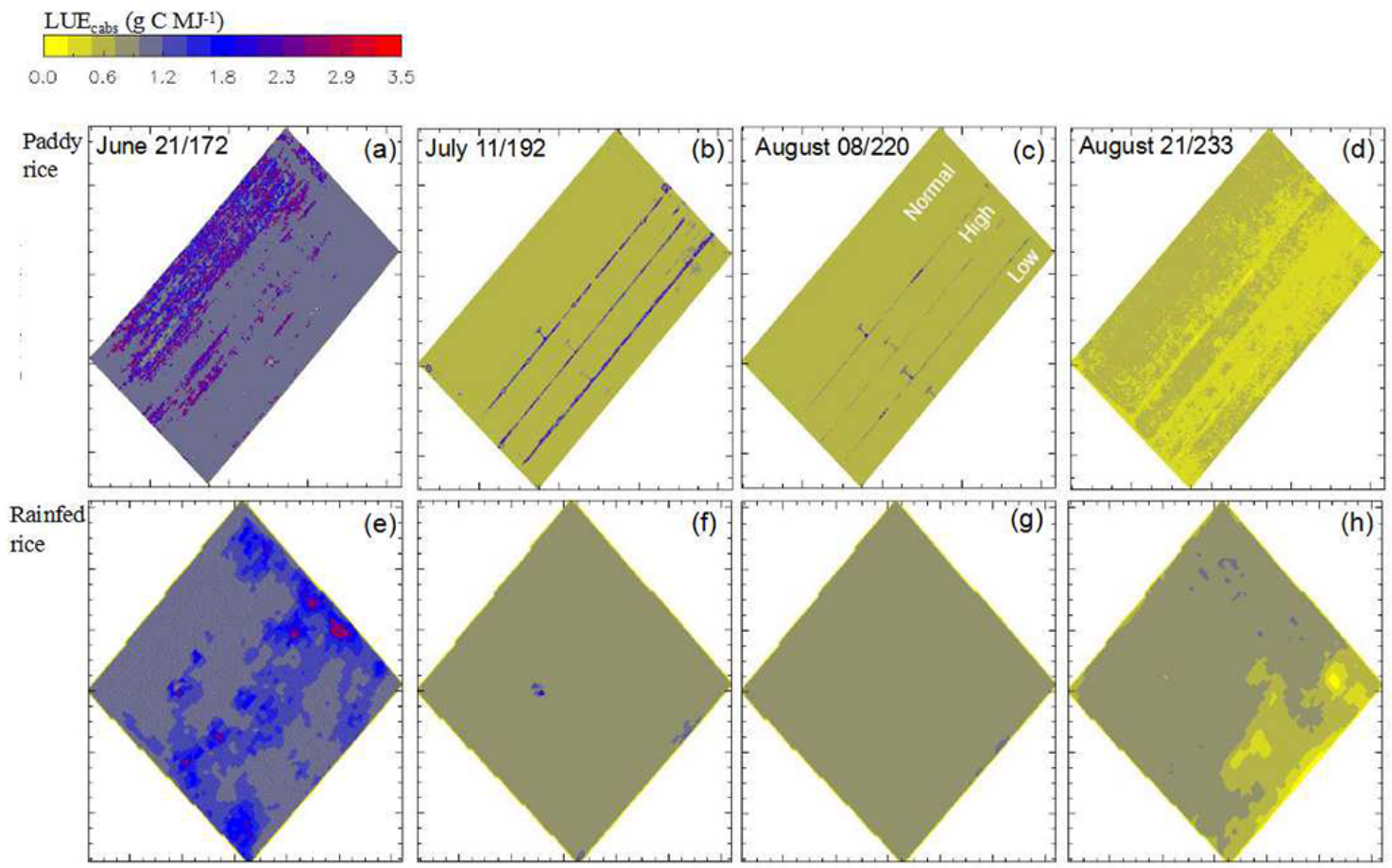

Figure 6. Field mapping of canopy light use efficiency $\left(\mathrm{LUE}_{\mathrm{cabs}}\right)$ in the PD rice and RF rice at principle growth stages: vegetative stage (21 June/172), middle reproductive stage (11 July/192), early ripening stage (8 August/220), and middle ripening stage (21 August/233). Date is expressed as MM DD/DOY. DOY: day of year; PD: paddy; RF: rainfed. 
8 August (DOY 220) and then declined with senescence. The maximum $\mathrm{GPP}_{\text {day }}$ predicted using a light use efficiency model in our previous report (Xue et al., 2016a) tended to be higher than the one shown here for the normal-nutrient group, which is thought to be due to model sensitivity to changes in ambient light environment.

Rice plants grown in the RF field showed significantly higher mean and maximum $\mathrm{GPP}_{\text {day }}$ than the PD rice at respective growth stages (Table 2). However, $\mathrm{CV}_{\text {traditional }}$ in the RF rice was about 2 times higher than the PD normaland low-nutrient groups several weeks after transplantation. The PD normal-nutrient group displayed a higher $\mathrm{CV}_{\text {traditional }}$ quantified on 21 June (DOY 172), followed by the high- and low-nutrient groups. Differences in $\mathrm{CV}_{\text {traditional }}$ among the PD nutrient groups disappeared over time, consistent with the color display in field map of GPP day in Fig. $5 c$ and d. The results suggested that although addition of fertilizer in the traditional way can promote increment of field average GPP day $_{\text {, }}$ it dramatically strengthened field variations of $\mathrm{GPP}_{\text {day }}$ during the early growth stage in the paddy field setting. As we expected, the change in planting culture from flooding to rainfed promoted the enhancement of field variations in the mean of field $\mathrm{GPP}_{\text {day }}$, probably due to the rising risk of soil water availability when prolonged drought events occur.

LUE $_{\text {cabs }}$ appeared to be higher early in the growing season; rapidly declined after plant growth and development advanced to the reproductive stage; and gradually decreased to approximately 0.52 and $0.81 \mathrm{~g} \mathrm{C} \mathrm{MJ}^{-1}$ at the senescence stage in the PD and RF rice, respectively (Table 2). The RF rice had clearly high values of average $\mathrm{LUE}_{\text {cabs }}$ as compared to the PD by approximately $21,35,26$, and $36 \%$ on 11 July, 25 July, 8 August, and 21 August, respectively, apart from 21 June, when the PD and RF showed similar LUE $\mathrm{L}_{\text {cabs }}$ of around $1.4 \mathrm{~g} \mathrm{C} \mathrm{MJ}^{-1}$. Enhanced $\mathrm{LUE}_{\text {cabs }}$ in the RF rice over the growing season was likely due to higher leaf nitrogen content as shown in Fig. 4a.

The seasonal course of $\mathrm{CV}_{\text {traditional }}$ of $\mathrm{LUE}_{\text {cabs }}$ among the PD nutrient groups exerted a similar tendency, assembling the mean of GPP day (Table 2). $\mathrm{CV}_{\text {traditional }}$ in the normaland high-nutrient groups was analogous over time, while appearing to be higher on 21 June (DOY 172) and 11 July (DOY 192) by approximately 62 and $50 \%$, respectively, than the low-nutrient group. Interestingly, $\mathrm{CV}_{\text {traditional }}$ in the fertilization groups (normal- and high-nutrient groups) displayed approximately 53 and $30 \%$ higher values, respectively, than the RF rice at the early growth stage (21 June/DOY 172 and 11 July/DOY 192). Similar to drought impacts in amplifying $\mathrm{CV}_{\text {traditional }}$ in $\mathrm{GPP}_{\text {day }}$ on 21 August (DOY 233) in the RF rice, amplified $\mathrm{CV}_{\text {traditional }}$ in $\mathrm{LUE}_{\text {cabs }}$ was also observed. Lower $C V_{\text {traditional }}$ and similarities in $\mathrm{LUE}_{\text {cabs }}$ over field space on 25 July (DOY 206) and 8 August (DOY 220) corresponded well to the field map of $\mathrm{LUE}_{\text {cabs }}$ at corresponding dates, meaning that field mapping in proper ways also could visibly deliver distribution information of ecosystem photosynthetic traits in space.

\subsection{Semi-variograms of $\mathrm{GPP}_{\text {day }}, \mathrm{LUE}_{\mathrm{cabs}}$, and LAI}

Semi-variogram analysis is a widely used geostatistical parameter to quantitatively evaluate spatial variation. Sill values were derived from exponential rise to maximum function, which fit the values of semi-variogram at each nutrient and/or water treatment $\left(R^{2}>0.83, p<0.01\right)$. Values of $\mathrm{CV}_{\text {sill }}$ in $\mathrm{GPP}_{\text {day }}$ were significantly and positively correlated with $\mathrm{CV}_{\text {traditional }}\left(R^{2}=0.83, p<0.001\right.$; Fig. 7a), demonstrating that the semi-variogram accurately captured patterns of spatial variability in those ecophysiological traits among the nutrient treatments and RF rice. Estimates of $\mathrm{CV}_{\text {sill }}$ among the nutrient groups were generally close to those of $\mathrm{CV}_{\text {traditional }}$, approaching the $1: 1$ line (Fig. 7a). However, $\mathrm{CV}_{\text {traditional }}$ values in the RF rice were commonly lower by approximately $20 \%$ than $\mathrm{CV}_{\text {sill }}$ at the principle growth stages. This occurred because the traditional method of calculating CV does not account for spatial correlation in data, suggesting that spatial heterogeneity in the RF field associated with water availability and resulting crop growth was greater than in the $\mathrm{PD}$ rice. This was also proven by averaged $\mathrm{CV}_{\text {sill }}$ in the RF that was greater by about $50 \%$ than that of the PD rice averaged across the nutrient groups (Table 3 ).

A significantly positive correlation between $\mathrm{CV}_{\text {sill }}$ and $\mathrm{CV}_{\text {traditional }}$ was observed in $\mathrm{LUE}_{\text {cabs }}$ as well $\left(R^{2}=0.89\right.$, $p<0.001$; Fig. 7b). All $\mathrm{CV}_{\text {sill }}$ sampled across the PD nutrient groups and RF rice resided at the right side of the $1: 1$ line, being higher than $\mathrm{CV}_{\text {traditional }}$ but analogous between the PD and RF rice, which was different from the significant difference in $\mathrm{CV}_{\text {sill }}$ of $\mathrm{GPP}_{\text {day }}$ between the PD and $\mathrm{RF}$ rice shown in Fig. 7a. It was also evident by average $\mathrm{CV}_{\text {sill }}$ of $11.66(\%)$ in the RF rice, which was close to the value of 14.37 of the PD rice averaged across nutrient groups (Table 3), meaning that spatial variability of $L E_{c a b s}$ in the PD rice exerted great amplitude that tended to be similar to the $\mathrm{RF}$ rice. A positively linear correlation between $\mathrm{CV}_{\text {sill }}$ and $\mathrm{CV}_{\text {traditional }}$ was evident in LAI $\left(R^{2}=0.80, p<0.001\right.$; Fig. 7c). Data points collected over the PD nutrient groups oscillated closely around the $1: 1$ line; an exception was observed in the RF rice, which reassembled the phenomena observed in the $\mathrm{CV}_{\text {sill }}-\mathrm{CV}_{\text {traditional }}$ relationship for $\mathrm{GPP}_{\text {day }}$ but differed from that for $\mathrm{LUE}_{\text {cabs. }}$. Given the tight correlation between $\mathrm{CV}_{\text {sill }}$ and sill values, sill instead of $\mathrm{CV}_{\text {sill }}$ was used in spatial analysis for $\mathrm{GPP}_{\text {day }}$ and $\mathrm{LUE}_{\text {cabs }}$ as discussed below.

\subsection{Spatial patterns of GPP $_{\text {day }}, \mathrm{LUE}_{\text {cabs }}$, and LAI}

Seasonal development in sill values of GPP $_{\text {day }}$ exhibited a similar tendency across the PD nutrient groups and RF rice, with an increase from the vegetative stage to the early reproductive stage followed by a decline (Table 3, upper part). A paired $t$ test across the range of DOY showed that difference of sill in the RF rice was significantly different from the PD nutrient groups $(p<0.05)$. Nevertheless, significant differences were not repeatedly observed among the PD nutrient 
Table 2. Descriptive statistics of $\mathrm{GPP}_{\text {day }}\left(\mathrm{g} \mathrm{C} \mathrm{m}^{-2} \mathrm{~d}^{-1}\right)$ and $\mathrm{LUE}_{\text {cabs }}\left(\mathrm{g} \mathrm{CMJ}^{-1}\right)$ at each nutrient treatment in the PD rice and at the RF rice over principle growing stages. Date is expressed as MM DD/DOY. DOY: day of year; PD: paddy; RF: rainfed.

\begin{tabular}{|c|c|c|c|c|c|c|c|c|}
\hline & \multicolumn{4}{|c|}{$\mathrm{GPP}_{\text {day }}$} & \multicolumn{4}{|c|}{ LUE $_{\text {cabs }}$} \\
\hline & Low & Normal & High & Rainfed & Low & Normal & High & Rainfed \\
\hline \multicolumn{9}{|l|}{21 June/172 } \\
\hline Mean & 2.32 & 2.56 & 2.33 & 4.53 & 1.16 & 1.67 & 1.43 & 1.3 \\
\hline $\operatorname{Max}$ & 3.78 & 7.29 & 3.51 & 10.57 & $\sim 3.50$ & $\sim 3.50$ & $\sim 3.50$ & 3.18 \\
\hline $\mathrm{CV}_{\text {traditional }}$ & $2.16 \%$ & $14.06 \%$ & $5.15 \%$ & $25.81 \%$ & $17.24 \%$ & $47.90 \%$ & $48.95 \%$ & $22.00 \%$ \\
\hline \multicolumn{9}{|l|}{11 July/192 } \\
\hline Mean & 6.16 & 9.57 & 8.35 & 10.99 & 0.68 & 0.62 & 0.73 & 0.86 \\
\hline Max & 11.21 & 12.73 & 11.97 & 16.93 & 1.72 & 2.75 & 2.86 & 2.35 \\
\hline $\mathrm{CV}_{\text {traditional }}$ & $21.36 \%$ & $14.52 \%$ & $20.37 \%$ & $26.32 \%$ & $4.92 \%$ & $11.29 \%$ & $9.20 \%$ & $7.09 \%$ \\
\hline \multicolumn{9}{|l|}{25 July/206 } \\
\hline Mean & 7.93 & 9.74 & 9.45 & 14.28 & 0.7 & 0.68 & 0.68 & 1.08 \\
\hline Max & 10.97 & 11 & 11.04 & 17.15 & 0.87 & 1.32 & 1.06 & 1.79 \\
\hline $\mathrm{CV}_{\text {traditional }}$ & $13.55 \%$ & $9.22 \%$ & $10.12 \%$ & $16.89 \%$ & $4.38 \%$ & $8.82 \%$ & $4.94 \%$ & $4.81 \%$ \\
\hline \multicolumn{9}{|l|}{8 August $/ 220$} \\
\hline Mean & 9.56 & 10.85 & 10.57 & 15.41 & 0.66 & 0.62 & 0.63 & 0.87 \\
\hline Max & 12.28 & 12.49 & 12.41 & 18.11 & 1.58 & 1.42 & 1.57 & 0.95 \\
\hline $\mathrm{CV}_{\text {traditional }}$ & $8.89 \%$ & $7.77 \%$ & $8.77 \%$ & $15.36 \%$ & $4.54 \%$ & $4.19 \%$ & $4.12 \%$ & $4.65 \%$ \\
\hline \multicolumn{9}{|c|}{21 August/233 } \\
\hline Mean & 7.13 & 7.69 & 7.45 & 12.14 & 0.49 & 0.52 & 0.52 & 0.81 \\
\hline Max & 9.94 & 10.73 & 10.22 & 15.91 & 0.66 & 0.71 & 0.68 & 1.05 \\
\hline $\mathrm{CV}_{\text {traditional }}$ & $9.23 \%$ & $8.49 \%$ & $8.88 \%$ & $19.91 \%$ & $6.93 \%$ & $7.69 \%$ & $6.73 \%$ & $19.75 \%$ \\
\hline
\end{tabular}

groups. Early in the growth season (i.e., 21 June/DOY 172 and especially on 11 July/DOY 192), the normal- and highnutrient groups had relatively high sill by an average of $44 \%$ as compared to the low-nutrient group, suggesting that fertilizer addition could contribute to spatial variability of $\mathrm{GPP}_{\text {day }}$, which conforms to differences in $\mathrm{CV}_{\text {traditional }}$ (Table 2). As expected, sill of the RF rice measured on $21 \mathrm{Au}-$ gust/DOY 233 increased in contrast to observed seasonal tendency of sill that was supposed to decline, due to occurrence of a prolonged drought event in mid-August during which time leaf water potential around solar noon declined to $-2.0 \mathrm{MPa}$ and severe leaf rolling occurred (data not shown). Significant impacts by drought on $\mathrm{GPP}_{\text {day }}$ were observed. Seasonal courses of sill in LAI across the PD nutrient groups and the RF rice were similar to those of $\mathrm{GPP}_{\text {day }}(\mathrm{Ta}-$ ble 3, middle part). Sills of LAI in the RF rice were generally higher than the PD rice at corresponding growth stages.

Sill of LUE $E_{\text {cabs }}$ showed a seasonal trend that was similar to GPP day (Table 3, lower part). The prolonged drought event occurring in August contributed to spatial variability in the RF rice as indicated by greater sill of 0.0142 compared with 0.0032 on 8 August (DOY 220). ANOVA indicated no difference at the 0.05 significance level among the three PD nutrient groups over the growing season $(p=0.67)$, whereas the mean sill value of 0.4492 on 21 June (DOY 172) was improved by approximately $94 \%$ for the normal- and highnutrient groups compared to the value of 0.03 for the lownutrient group, resembling comparisons in sill of $\mathrm{GPP}_{\text {day }}$ and field maps shown in Fig. 6a. The results implied that fertilizer addition can enhance spatial variability of $\mathrm{LUE}_{\text {cabs }}$ especially early in the growing season. Interestingly, at the early growth stage, especially on 21 June (DOY 172) and 11 July (DOY 192), the PD nutrient addition groups had average sill values that were approximately $85 \%$ than the RF rice. Thereafter the values of RF rice became greater, meaning that spatial variability of $L E_{c a b s}$ in the PD rice amplified by field nutrient application could be even greater than the RF rice, in contrast with aforementioned $\mathrm{GPP}_{\text {day }}$ spatial variability between the PD and RF rice.

\subsection{Spatial correlation for $G_{P P}$ day,$L E_{c a b s}$, and LAI}

$L E_{\text {cabs }}$ was calculated by Eq. (8), consisting of GPP ${ }_{\text {day }}$ and fAPAR variables, meaning that spatial variations of $L E_{\text {cabs }}$ may greatly influence $\mathrm{GPP}_{\text {day }}$. Sill values or $\mathrm{CV}_{\text {sill }}$ for $\mathrm{GPP}_{\text {day }}$ and $\mathrm{LUE}_{\text {cabs }}$ were not significantly correlated with one another when all data sets were grouped across 

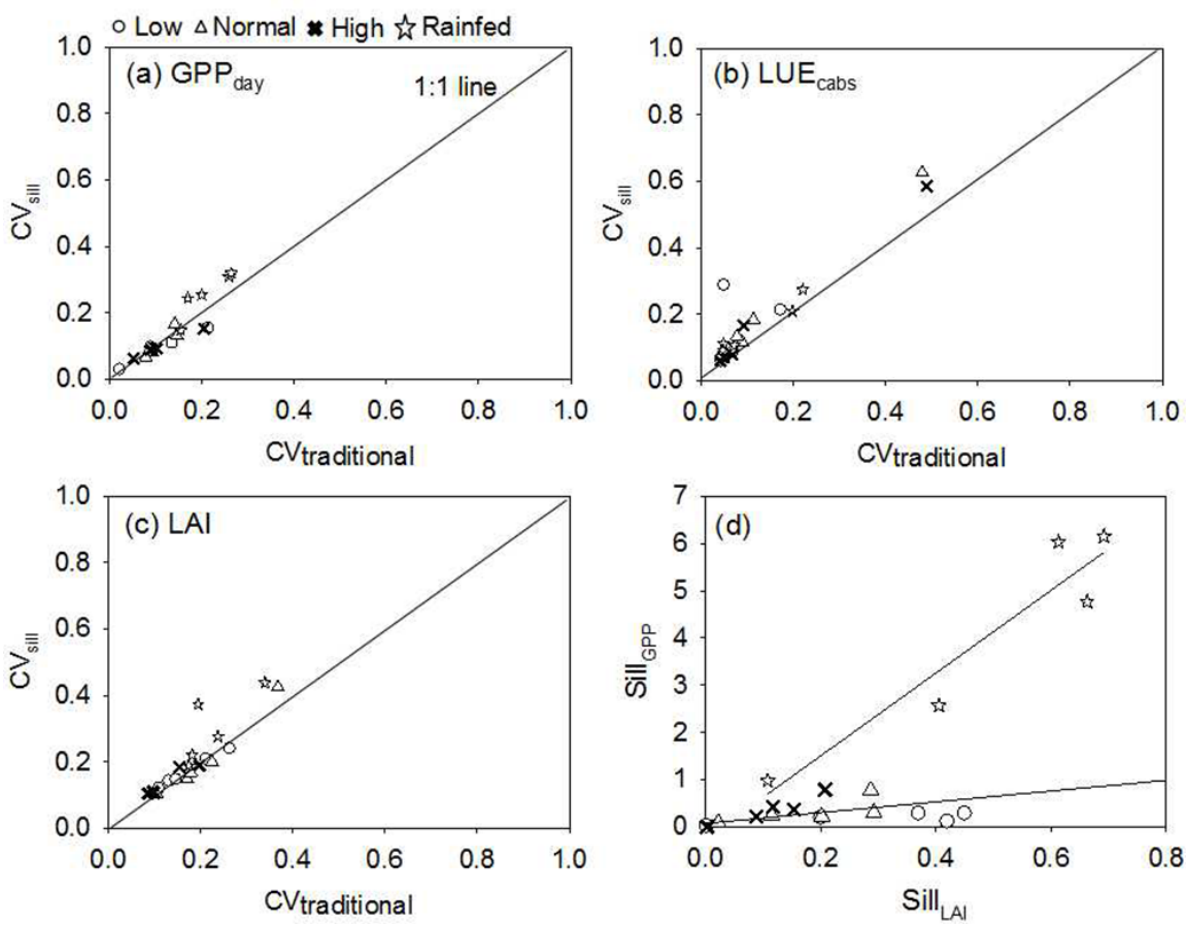

Figure 7. Coefficient of variation $\left(\mathrm{CV}_{\text {traditional }}\right)$ calculated by dividing the standard deviation by the mean versus coefficient of variation $\left(\mathrm{CV}_{\text {sill }}\right)$ calculated using the semi-variogram sill across the PD nutrient groups and the RF rice for variables (a) $\mathrm{GPP}_{\text {day }}$, (b) LUE $\mathrm{b}_{\mathrm{cabs}}$, and

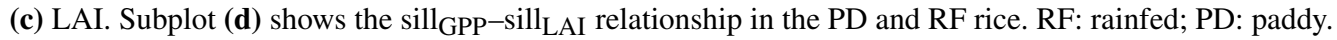

Table 3. Sill values of semi-variograms and $\mathrm{CV}_{\text {sill }}$ for $\mathrm{GPP}_{\text {day }}\left(\mathrm{g} \mathrm{C} \mathrm{m}^{-2} \mathrm{~d}^{-1}\right.$, upper part), LAI ( $\mathrm{m}^{2} \mathrm{~m}^{-2}$, middle part), and LUE ( $\mathrm{g} \mathrm{C} \mathrm{MJ}^{-1}$, lower part) at the PD rice subject to low, normal, and high nitrogen gradients and at the RF rice over the principle growing seasons: vegetative stage (21 June), reproductive stage (11 and 25 July), ripening stage (8 and 21 August). Date is expressed as MM DD/DOY. DOY: day of year; PD: paddy; RF: rainfed.

\begin{tabular}{llrrrrrrrr}
\hline Growth stage & Date/DOY & \multicolumn{2}{c}{ Low } & \multicolumn{2}{c}{ Normal } & \multicolumn{2}{c}{ High } & \multicolumn{2}{c}{ Rainfed } \\
\hline $\mathrm{GPP}_{\text {day }}$ & & Sill & $\mathrm{CV}_{\text {sill }}$ & Sill & $\mathrm{CV}_{\text {sill }}$ & Sill & $\mathrm{CV}_{\text {sill }}$ & Sill & $\mathrm{CV}_{\text {sill }}$ \\
\hline Vegetative & 21 June/172 & 0.01 & $2.86 \%$ & 0.09 & $16.57 \%$ & 0.01 & $6.10 \%$ & 0.98 & $30.91 \%$ \\
Reproductive & 11 July/192 & 0.45 & $15.40 \%$ & 0.78 & $13.05 \%$ & 0.79 & $15.05 \%$ & 6.15 & $31.91 \%$ \\
& 25 July/206 & 0.37 & $10.85 \%$ & 0.31 & $8.08 \%$ & 0.37 & $9.10 \%$ & 6.03 & $24.32 \%$ \\
Ripening & 8 August/220 & 0.42 & $9.59 \%$ & 0.25 & $6.52 \%$ & 0.43 & $8.77 \%$ & 2.57 & $14.71 \%$ \\
& 21 August/233 & 0.20 & $8.87 \%$ & 0.23 & $8.82 \%$ & 0.22 & $8.90 \%$ & 4.77 & $25.44 \%$ \\
\hline LAI & & & & & & & & & \\
\hline Vegetative & 21 June/172 & 0.0015 & $14.19 \%$ & 0.0219 & $42.48 \%$ & 0.0026 & $18.40 \%$ & 0.1079 & $43.75 \%$ \\
Reproductive & 11 July/192 & 0.1111 & $20.81 \%$ & 0.2869 & $19.96 \%$ & 0.2076 & $18.91 \%$ & 0.6915 & $37.36 \%$ \\
& 25 July/206 & 0.1866 & $14.68 \%$ & 0.2924 & $14.76 \%$ & 0.1535 & $10.71 \%$ & 0.6127 & $22.07 \%$ \\
Ripening & 8 August/220 & 0.4306 & $23.99 \%$ & 0.1148 & $10.10 \%$ & 0.1174 & $10.37 \%$ & 0.4050 & $18.83 \%$ \\
& 21 August/233 & 0.0910 & $12.02 \%$ & 0.2015 & $16.72 \%$ & 0.0879 & $11.14 \%$ & 0.6622 & $27.59 \%$ \\
\hline LUE & & & & & & & & & \\
\hline Vegetative & 21 June/172 & 0.0302 & $21.19 \%$ & 0.5478 & $62.68 \%$ & 0.3506 & $58.56 \%$ & 0.0633 & $27.37 \%$ \\
Reproductive & 11 July/192 & 0.0190 & $28.67 \%$ & 0.0065 & $18.39 \%$ & 0.0073 & $16.55 \%$ & 0.0041 & $10.53 \%$ \\
& 25 July/206 & 0.0008 & $5.71 \%$ & 0.0031 & $11.58 \%$ & 0.0011 & $6.90 \%$ & 0.0070 & $10.96 \%$ \\
Ripening & 8 August/220 & 0.0011 & $7.11 \%$ & 0.0010 & $7.21 \%$ & 0.0007 & $5.94 \%$ & 0.0032 & $9.20 \%$ \\
& 21 August/233 & 0.0009 & $8.66 \%$ & 0.0024 & $13.32 \%$ & 0.0008 & $7.69 \%$ & 0.0142 & $20.81 \%$ \\
\hline
\end{tabular}


the PD nutrient groups and RF rice over the growing season $\left(R^{2}<0.14, p>0.01\right)$. Significantly positive correlations were found for the sill ${ }_{\mathrm{GPP} \text { day }}-$ sill $_{\mathrm{LAI}}$ relationship in the PD nutrient groups (Fig. 7d; $R^{2}=0.36, p=0.012$ ) and in the RF rice (Fig. $7 d ; R^{2}=0.85, p=0.015$ ), suggesting that the primary factor that mediated $\mathrm{GPP}_{\text {day }}$ spatial variation in the PD nutrient groups, especially in the RF rice, was LAI development.

\subsection{Implied ecological implications of canopy leaf physiology}

Ecological implications of canopy leaf physiology (i.e., $\mathrm{LUE}_{\text {cabs }}$ ) in monitoring of spatial variation and strength of $\mathrm{GPP}_{\text {day }}$ for the same plant function type (PD and RF rice) were analyzed using scenario analysis. The analysis applied $\mathrm{LUE}_{\text {cabs }}$ of the PD rice on 8 August (DOY 220) in the estimation of the $\mathrm{RF}$ rice $\mathrm{GPP}_{\text {day }}$ on the same date, yielding comparisons in field map of $\mathrm{GPP}_{\text {day }}$ (Fig. 8a, b) and quantitative assessment (Fig. 8c). The field map of predicted GPP day

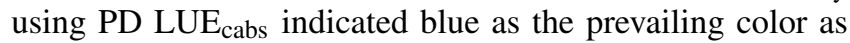
compared to the prevailing red color in the field map of the initial estimation, indicating a significant underestimation of $\mathrm{GPP}_{\text {day }}$ especially at the sites showing high LAI (Fig. 8c). The results suggested that delicate variations in canopy leaf physiology among the same plant function type across various habitat conditions are vital.

\section{Discussions}

A series of successive effects regarding rice growth and environment perspectives from the leaf to the ecosystem have been revealed in our research group, with the aim of clarifying the physiological mechanisms responsible for optimal carbon gain and water use at the leaf level as well as their plastic acclimation to changing ambient environments (Xue et al., 2016b, c); discerning the roles of canopy structure and function in determining canopy carbon gain in individual organisms in different field management conditions and anthropogenic interventions (Lindner et al., 2016; Xue et al., 2016a); increasing the understanding of the influences of climate change, phenology, and rice ecosystem photosynthetic productivity (Xue et al., 2017); and facilitating a discussion of the ecological implications of the life history of rice crops in controlling regional carbon fluxes in the agriculture landscape (Lindner et al., 2015). There are large fluctuations of ecosystem photosynthetic productivity at different geographic sites. However, the fluctuations have not been statistically correlated with the rate of $\mathrm{N}$ application, which does significantly contribute to rice growth at the individual level. This is thought to be due to various factors, including inter- and intra-field variations of ecosystem photosynthetic productivity. This highlights the need for field/micrositedirected research to gain new insights into how water and
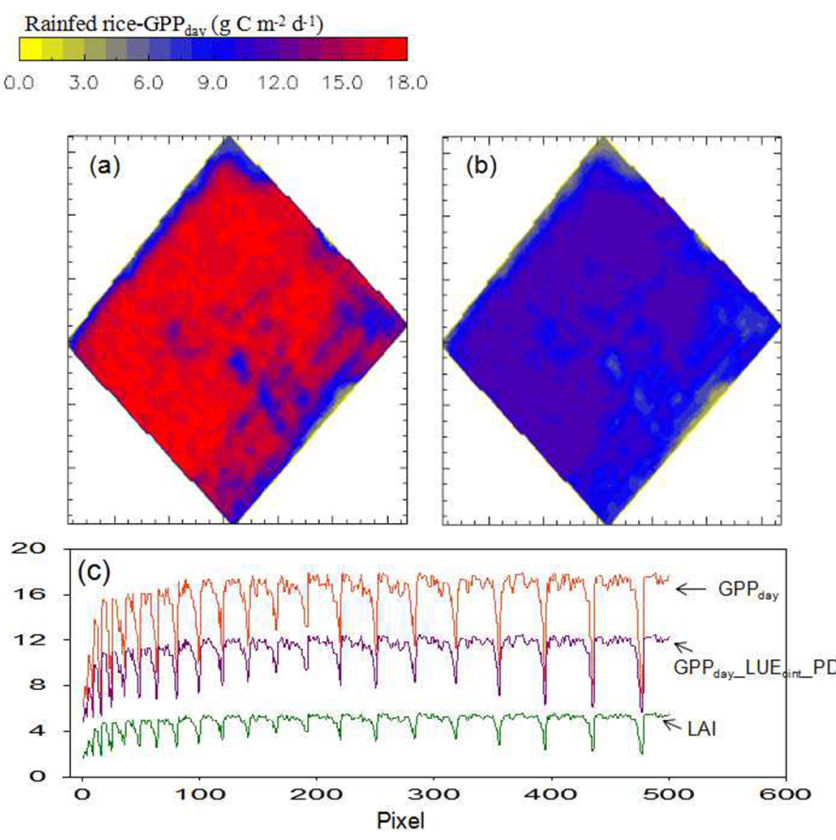

Figure 8. Effects of light use efficiency ( $\left.\mathrm{LUE}_{\mathrm{cint}}\right)$ on estimation of daily integrated photosynthetic productivity $\left(\mathrm{GPP}_{\text {day }}\right)$ at ripening stage in the RF rice. GPP day estimation using (a) observed $\mathrm{LUE}_{\text {cint }}$ in the RF rice, (b) $\mathrm{LUE}_{\text {cint }}$ of the PD rice $\left(\mathrm{GPP}_{\text {day_LUE }} \mathrm{E}_{\text {cint_PD); }} \mathrm{PD}\right.$ i.e., $\mathrm{GPP}_{\text {day }}$ estimation of the RF rice was carried out by adopting the $\mathrm{LUE}_{\text {cint }}$ value of the PD rice at the ripening stage. (c) Quantitative comparisons between $\mathrm{GPP}_{\text {day }}$ and $\mathrm{GPP}_{\text {day_LUE }}$ cint_PD based on pixel LAI. PD: paddy; RF: rainfed.

$\mathrm{N}$ availability affect photosynthetic productivity at individual and microsite scales.

\subsection{Feasible application of the UAV system to capture spatiotemporal variations of $\mathbf{G P P}_{\text {day }}$}

Applications of close-range remote sensing in studies of vegetation dynamics regarding plant growth and phenology have been increasingly explored, partially due to smallscale pixel-to-pixel detection that eliminates the averaging involved in larger pixels. It compensates for the regional observations of a satellite remote-sensing system. UAV-based applications in agronomical studies has been tested and include evaluation of spatial variability of soil $\mathrm{N}$ content in a winter wheat field (Cao et al., 2012), detection of canopy $\mathrm{N}$ status in irrigated maize (Bausch and Khosla, 2010), and mapping of cereal yield using field vegetation indices (Fisher et al., 2009; Swain et al., 2010; Tubaña et al., 2012; Zhang and Kovacs, 2012) with rice growth and yield included (Ko et al., 2015). Recent attempts were made to apply narrow-band multispectral imagery derived at the plot level in monitoring of whole field C content of lucerne plants (Wehrhan et al., 2016). Furthermore, an applicable crop information delivery system tested in rice ecosystems by Ko et al. (2015) and Jeong et al. (2016), which took several valuable high-spatial- 
resolution vegetation indices into account, captured delicate changes in crop growth and yield among the pixels. In this research, diagnostic information derived from high-spatialresolution images could be strongly linked to canopy biophysical traits in the paddy and rainfed rice, allowing seasonally zonal maps of $\mathrm{GPP}_{\text {day }}$ and $\mathrm{LUE}_{\text {cabs }}$ to be made (Figs. 5 and 6), and assisting in the evaluation of spatial variation of those functional traits.

Practical application of the UAV technique in the field requires a number of procedural steps. They include image preprocessing, image interpretation, and data extraction. Integration of the data with agronomic data in expert systems still needs to be developed and improved before end products can be germane for decision making (Zhang and Kovacs, 2012). An empirical calibration method adopting spectral reflectance from three types of PITs was applied to process radiometric correction of UAV images on each measuring date. Although calibrated UAV reflectance and atsurface measurements usually closely corresponded during the middle and late growing seasons, the empirical calibration tended to underestimate ground reflectance especially in red reflectance at the early growth stage. This was probably due to water scattering effects. The UAV flight schedule that is always scheduled at solar noon may not be the best option to obtain a close correspondence between camera reflectance and ground surface measurements at the early growth stage. Another empirical regression linking radiometrically calibrated UAV images and plot measurements was applied instead of considering complex mechanisms of light scattering in the area of physical category. The methods used to recalibrate UAV images on 21 June (DOY 172) may yield biased estimations of field reflectance due to the limited number of ground reflectance swatches that were deployed in the limited space. Leaves of plants grown under fertilizer addition conditions had higher $\mathrm{N}$ content at the early growth stage, resulting in greater $\mathrm{LUE}_{\text {cabs }}$ (Sinclair and Horie, 1989; Xue et al., 2017). On average, $\mathrm{LUE}_{\mathrm{cabs}}$ in the fertilization groups where plants accumulated more $\mathrm{N}$ in leaves on 21 June (Fig. 4a) was higher than in the low-nutrient group (Table 2), which implies the pragmatic feasibility of adopting the recalibration routine to acquire correct UAV products.

The data fitting concept that integrates traditional physiology approaches at the plot level and close-range remotesensing information requires reliable establishments regarding correlations between ground surface measurements of VIs and LAI, LAI and $\mathrm{LUE}_{\text {cint }}$, and $\mathrm{GPP}_{\max }$. Reliable relationships between those biophysical traits were inferred across the paddy and rainfed rice (Fig. 3). Nevertheless, data sets for the LAI-LUE $\mathrm{E}_{\text {cint }}$ correlation in the rainfed rice were limited mainly due to the difficulty in physically performing measurements of diurnal courses of leaf and canopy gas exchange and measurements of other plant parameters in the paddy nutrient groups and rainfed rice. Supplement data sets

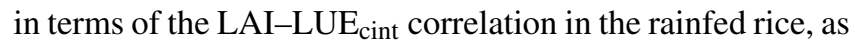

well as other main crops, will be conducted as the technical barriers are overcome.

\subsection{Spatial variability of photosynthetic trait in the rainfed field is not always greater than in the paddy field}

The burgeoning global population continues to increase the demand for water and food staples, including rice. Furthermore, the looming specter of water scarcity in the coming decades in some regions now capable of flooding of crop fields highlights the need for turning flooding culture into multicultural management, including the paddy and rainfed systems. The expansion of rice planting to different geographic sites, particularly in regions lacking the capability of irrigation and/or flooding of crop fields is always featured by large variations of seasonal photosynthetic productivity (Serraj et al., 2008). Therefore, a critical concern related to the reported observation is how water availability in the rainfed fields could influence spatiotemporal variations of ecosystem photosynthetic productivity as compared to paddy fields. In the present study, spatial variations of $\mathrm{GPP}_{\text {day }}$ and LAI in the rainfed field were amplified compared to the paddy nutrient groups at corresponding growth stages (Table 3). However, spatial variation of $\mathrm{LUE}_{\text {cabs }}$ at the early growth stage (21 June/DOY 172 and 11 July/DOY 192) in the paddy fertilization groups was significantly greater than the rainfed rice at the same times, suggesting that spatial variability of the photosynthetic trait in the rainfed field does not always exceed that of paddy fields, depending on nutrient availability. Furthermore, nutrient addition at the early growth stage could amplify spatial heterogeneity of $\mathrm{GPP}_{\text {day }}$ and $\mathrm{LUE}_{\text {cabs }}$ in the paddy field, while such nutritional effects are dismissed at reproductive and ripening stages.

\subsection{Implied ecological implications of field niche in a spatially hierarchical remote-sensing network}

In situ plot data are important for the accurate interpretation of ecosystem carbon dynamics in response to different field management methods and anthropogenic interventions that involve influences on plant structure and physiology. While plot data provide the most detailed information on rice carbon and water vapor gas exchange, applying this understanding to broader spatial and temporal domains requires scaling approaches. As mentioned before, the field niche between in situ plot and regional dimension is supposed to be a key chain of a spatially hierarchical remote-sensing network (Masek et al., 2015; Pause et al., 2016). Applications of the data fusion at the microsite/field scale that combine observations of in situ canopy structure and function with field crop information derived from the UAV system capture critical growth information of rice crop in space.

Spatial variations in $\mathrm{GPP}_{\text {day }}$ over the paddy nutrient groups and rainfed rice tend to be primarily mediated by 
LAI. Canopy structure (i.e., LAI) is the main biotic factor in paddy rice ecosystems, yielding a great impact on the seasonal course of ecosystem photosynthetic productivity (Xue et al., 2017). Variations of the overall growing season photosynthetic productivity are significantly mediated by fluctuations of daily GPP at the ripening stage when canopy LAI is maximized. The scenario analysis in Fig. 8 documented marked underestimations of $\mathrm{GPP}_{\text {day }}$ in the rainfed rice at the beginning of the ripening stage when applying $\mathrm{LUE}_{\mathrm{cabs}}$ of the paddy rice in spatial monitoring of $\mathrm{GPP}_{\text {day }}$ in the rainfed field. Enhanced LUE ${ }_{\text {cabs }}$ after DOY 180 in the rainfed rice could be primarily ascribed to greater capacity of $\mathrm{N}$ accumulation (Fig. 4) and/or to efficient P uptake (Kato et al., 2016) that was not quantified here. Changes in leaf N allocation within leaves that relate to photosynthetic activity of individual leaves may also have important implications like plant biomass production (Karaba et al., 2007; Wang et al., 2014) or may not affect biomass (Tanaka et al., 2013; Dow and Bergmann, 2014), and they must be investigated along with canopy structure. There is a need to consider variations in canopy leaf physiology for the same plant function type across various habitat conditions. The results will hopefully assist in better monitoring of per-field photosynthetic productivity and biological interpretation of its spatial patterns using the remote-sensing technique.

\section{Conclusions}

As far as we know, this is the first work aiming to assess influences of $\mathrm{N}$ and water availability in spatial and temporal patterns of ecosystem photosynthetic productivity at the microscale. Abundant and high-quality data derived from the close-range remote-sensing system refract crop growth information linked to biotic and abiotic factors at critical growth stages. Fertilizer addition in the paddy rice field enhanced spatial variations of GPP day $_{\text {and }}$ LAI as well as $\mathrm{LUE}_{\text {cabs }}$ during the early growing stage. A change of planting culture from flooding to rainfed conditions contributed to their spatial heterogeneity in space. Nevertheless, nutritional effects in the paddy rice at the early growth stage with greater spatial variations of $L_{U E} E_{\text {cabs }}$ than the rainfed field were evident. The physiological basis related to $\mathrm{LUE}_{\text {cabs }}$ in the rainfed rice and its contribution in determination of daily GPP highlight that taking delicate changes in canopy leaf physiology in space for the same plant function type into account could add to our understanding of interannual fluctuations of ecosystem photosynthetic productivity at agricultural landscapes.

Data availability. Most raw data has been shown in Figs. 2, 3, 4. Abundant UAV remote sensing data such as NDVI could be accessible when directly contact the first correspondence author. 


\section{Appendix A}
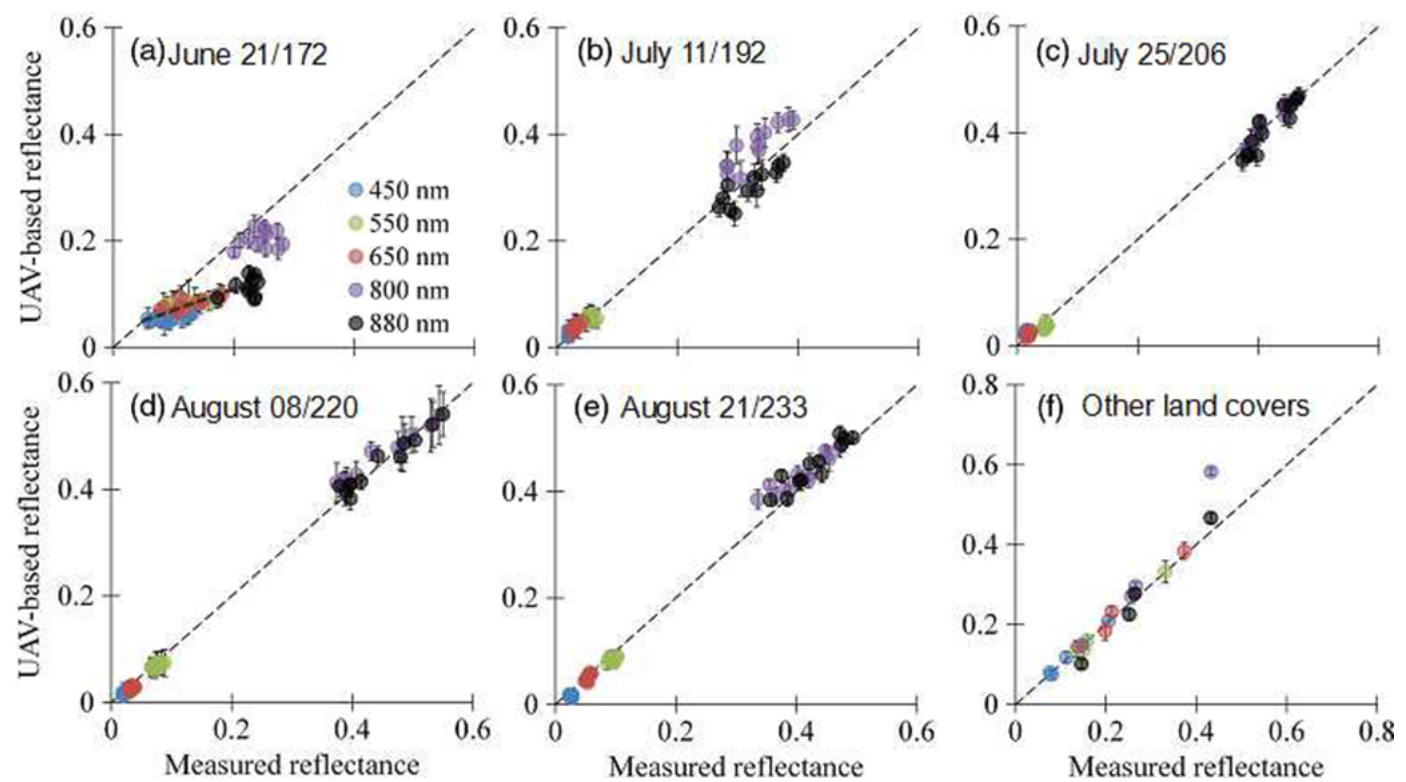

Figure A1. Validation of radiometrically calibrated UAV-based reflectance by measurements of group point reflectance set up in paddy fields across the whole growing season (a-e) and in other land covers obtained on day of year (DOY) 172, 192, and 220 including bright cement, dark asphalt, bare soil, and tilled soil (f). Dashed line in each subplot shows 1:1 ratio. Recalibration for UAV-based reflectance in red waveband was conducted on 21 June (DOY 172), shown in subplot a (coarse dashed line). 
Competing interests. The authors declare that they have no conflict of interest.

Acknowledgements. This study was supported by the Basic Science Research Program through the National Research Foundation of Korea (NRF), funded by the Ministry of Education, Science, and Technology (NRF-2013R1A2005788). We thank the agricultural logistics group of CNU for the field management. We acknowledge the help in the field by Steve Lindner, Bhone Nay-Htoon, Jinsil Choi, Seung Hyun Jo, Toncheng Fu, Fabian Fischer, Nikolas Lichtenwald, and Yannic Ege. We gratefully acknowledge the technical assistance of Margarete Wartinger for all her support in the field and laboratory.

Edited by: P. Stoy

Reviewed by: two anonymous referees

\section{References}

Adiku, S., Reichstein, M., Lohila, A., Dinh, N., Aurela, M., Laurila, T., Lueers, J., and Tenhunen, J.: PIXGRO: a model for simulating the ecosystem $\mathrm{CO}_{2}$ exchange and growth of spring barley, Ecol. Model., 190, 260-276, 2006.

Alton, P. B.: Retrieval of seasonal Rubisco-limited photosynthetic capacity at global FLUXNET sites from hyperspectral satellite remote sensing: impact on carbon modelling, Agr. Forest Meteorol., 232, 74-88, 2017.

Bausch, W. and Khosla, R.: QuickBird satellite versus groundbased multi-spectral data for estimating nitrogen status of irrigated maize, Precis. Agric., 11, 274-290, 2010.

Cao, Q., Cui, Z., Chen, X., Khosla, R., Dao, T. H., and Miao, Y.: Quantifying spatial variability of indigenous nitrogen supply for precision nitrogen management in small scale farming, Precis. Agric., 13, 45-61, 2012.

Devendra, C.: Small farm system to feed hungry Asia, Outlook Agric., 36, 17-20, 2007.

Dow, G. J. and Bergmann, D. C.: Patterning and processes: how stomatal development defines physiological potential, Curr. Opin Plant Biol., 21, 67-74, 2014.

Fisher, P., Abuzar, M., Rab, M., Best, F., and Chandra, S.: Advances in precision agriculture in south-eastern Australia, I. A regression methodology to simulate spatial variation in cereal yields using farmers' historical paddock yields and normalised difference vegetation index, Crop Pasture Sci., 60, 844-858, 2009.

Forkel, M., Carvalhais, N., Rödenbeck, C., Keeling, R., Heimann, M., Thonicke, K., Zaehle, S., and Reichstein, M.: Enhanced seasonal $\mathrm{CO}_{2}$ exchange caused by amplified plant productivity in northern ecosystems, Science, 351, 696-699, 2016.

Inoue, Y., Peñuelas, J., Miyata, A., and Mano, M.: Normalized difference spectral indices for estimating photosynthetic efficiency and capacity at a canopy scale derived from hyperspectral and $\mathrm{CO}_{2}$ flux measurements in rice, Remote Sens. Environ., 112, 156-172, 2008.

Jeong, S., Ko, J., Kim, M., and Kim, J.: Construction of an unmanned aerial vehicle remote sensing system for crop monitoring, J. Appl. Remote Sens., 10, doi:10.1117/1.JRS.10.026027, 2016.
Jo, S. H. and Ko, J. H.: Determining canopy growth conditions of paddy rice via ground-based remote sensing, Korea J. Remote Sens., 31, 11-20, 2015.

Karaba, A., Dixit, S., Greco, R., Aharoni, A., Trijatmiko, K. R., Marsch-Martinez, N., Krishnan, A., Nataraja, K. N., Udayakumar, M., and Pereira, A.: Improvement of water use ef?ciency in rice by expression of HARDY, an Arabidopsis drought and salt tolerance gene, P. Natl. Acad. Sci. USA, 104, 15270-15275, 2007.

Kato, Y., Tajima, R., Toriumi, A., Homma, K., Moritsuka, N., Shiraiwa, T., Yamagishi, J., Mekwatanakern, P., Chamarerk, V., and Jongdee, B.: Grain yield and phosphorus uptake of rainfed lowland rice under unsubmerged soil stress, Field Crop. Res., 190, 54-59, 2016.

Kim, K. Y., Ha, K. Y., Ko, J. C., Choung, J. I., Lee, J. K., Ko, J. K., Kim, B. K., Nam, J. K., Shin, M. S., and Choi, Y. H.,: A new early maturity rice cultivar, "Unkwang" with high grain quality and cold tolerance, Korea J. Breed., 38, 261-262, 2006.

Ko, J., Jeong, S., Yeom, J., Kim, H., Ban, J. O., and Kim, H. Y.: Simulation and mapping of rice growth and yield based on remote sensing, J. Appl. Remote Sens., 9, 096067, doi:10.1117/1.JRS.9.096067, 2015.

Kwon, H., Kim, J., Hong, J., and Lim, J.-H.: Influence of the Asian monsoon on net ecosystem carbon exchange in two major ecosystems in Korea, Biogeosciences, 7, 1493-1504, doi:10.5194/bg-7-1493-2010, 2010.

Lausch, A., Bannehr, L., Beckmann, M., Boehm, C., Feilhauer, H., Hacker, J., Heurich, M., Jung, A., Klenke, R., and Neumann, C.: Linking earth observation and taxonomic, structural and functional biodiversity: local to ecosystem perspectives, Ecol. Indic., 70, 317-339, 2016.

Lee, B.: Remote sensing-based assessment of gross primary production in agricultural ecosystems, in: Ph.D Thesis, University of Bayreuth, 134 pp., 2014.

Lindner, S., Otieno, D., Lee, B., Xue, W., Arnhold, S., Kwon, H., Huwe, B., and Tenhunen, J.: Carbon dioxide exchange and its regulation in the main agro-ecosystems of Haean catchment in South Korea, Agr. Ecosyst. Environ., 199, 132-145, 2015.

Lindner, S., Xue, W., Nay-Htoon, B., Choi, J., Ege, Y., Lichtenwald, N., Fischer, F., Ko, J., Tenhunen, J., and Otieno, D.: Canopy scale $\mathrm{CO}_{2}$ exchange and productivity of transplanted paddy and direct seeded rainfed rice production systems in S. Korea, Agr. Forest Meteorol., 228, 229-238, 2016.

Loescher, H., Ayres, E., Duffy, P., Luo, H., and Brunke, M.: Spatial variation in soil properties among North American ecosystems and guidelines for sampling designs, Plos One, 9, e83216, doi:10.1371/journal.pone.0083216, 2014.

Masek, J. G., Hayes, D. J., Hughes, M. J., Healey, S. P., and Turner, D. P.: The role of remote sensing in process-scaling studies of managed forest ecosystems, Forest Ecol. Manag., 355, 109-123, 2015.

Niinemets, Ü. and Tenhunen, J.: A model separating leaf structural and physiological effects on carbon gain along light gradients for the shade-tolerant species Acer saccharum, Plant Cell Environ., 20, 845-866, 1997.

Pause, M., Schweitzer, C., Rosenthal, M., Keuck, V., Bumberger, J., Dietrich, P., Heurich, M., Jung, A., and Lausch, A.: In situ/remote sensing integration to assess forest health-a review, Remote Sens., 8, 471, doi:10.3390/rs8060471, 2016. 
Pierson, F. B. and Wight, J. R.: Variability of near-surface soil temperature on sagebrush rangeland, J. Range Manage., 44, 491497, 1991.

Richardson, A. D., Keenan, T. F., Migliavacca, M., Ryu, Y., Sonnentag, O., and Toomey, M.: Climate change, phenology, and phenological control of vegetation feedbacks to the climate system, Agr. Forest Meteorol., 169, 156-173, 2013.

Swain, K. C., Thomson, S. J., and Jayasuriya, H. P.: Adoption of an unmanned helicopter for low-altitude remote sensing to estimate yield and total biomass of a rice crop, T. ASABE, 53, 21-27, 2010.

Seo, B., Bogner, C., Poppenborg, P., Martin, E., Hoffmeister, M., Jun, M., Koellner, T., Reineking, B., Shope, C. L., and Tenhunen, J.: Deriving a per-field land use and land cover map in an agricultural mosaic catchment, Earth Syst. Sci. Data, 6, 339-352, doi:10.5194/essd-6-339-2014, 2014.

Serraj, R., Bennett, J., and Hardy, B.: Drought frontiers in rice: crop improvement for increased rainfed production, International Rice Research Institute, Manila, Philippines, 385 pp., 2008.

Sinclair, T. and Horie, T.: Leaf nitrogen, photosynthesis, and crop radiation use efficiency: a review, Crop Sci., 29, 90-98, 1989.

Steudle, E.: Water uptake by roots: effects of water deficit, J. Exp. Bot., 51, 1531-1542, 2000.

Tanaka, Y., Sugano, S. S., Shimada, T., and Hara-Nishimura, I.: Enhancement of leaf photosynthetic capacity through increased stomatal density in Arabidopsis, New Phytol., 198, 757-764, 2013.

Tenhunen, J., Geyer, R., Adiku, S., Reichstein, M., Tappeiner, U., Bahn, M., Cernusca, A., Dinh, N., Kolcun, O., and Lohila, A.: Influences of changing land use and $\mathrm{CO}_{2}$ concentration on ecosystem and landscape level carbon and water balances in mountainous terrain of the Stubai Valley, Austria, Glob. Planet. Change, 67, 29-43, 2009.

Tubaña, B., Harrell, D., Walker, T., Teboh, J., Lofton, J., and Kanke, Y.: In-season canopy reflectance-based estimation of rice yield response to nitrogen, Agron. J., 104, 1604-1611, 2012.
Van Genuchten, M. T.: A closed-form equation for predicting the hydraulic conductivity of unsaturated soils, Soil Sci. Soc. Am. J., 44, 892-898, 1980.

Vieira, S., Hatfield, J., Nielsen, D., and Biggar, J.: Geostatistical theory and application to variability of some agronomical properties, Hilgardia, 51, 1-75, 1983.

Wang, Y., Noguchi, K., Ono, N., Inoue, S., Terashima, I., and Kinoshita, T.: Overexpression of plasma membrane H+-ATPase in guard cells promoteslight-induced stomatal opening and enhances plant growth, P. Natl. Acad. Sci. USA, 111, 533-538, 2014.

Wehrhan, M., Rauneker, P., and Sommer, M.: UAV-based estimation of carbon exports from heterogeneous soil landscapes-a case study from the CarboZALF experimental area, Sensors, 16, 255, doi:10.3390/s16020255, 2016.

Xue, W., Lindner, S., Nay-Htoon, B., Dubbert, M., Otieno, D., Ko, J., Muraoka, H., Werner, C., Tenhunen, J., and Harley, P.: Nutritional and developmental influences on components of rice crop light use efficiency, Agr. Forest Meteorol., 223, 1-16, $2016 \mathrm{a}$.

Xue, W., Nay-Htoon, B., Lindner, S., Dubbert, M., Otieno, D., Ko, J., Werner, C., and Tenhunen, J.: Soil water availability and capacity of nitrogen accumulation influence variations of intrinsic water use efficiency in rice, J. Plant Physiol., 193, 26-36, $2016 \mathrm{~b}$.

Xue, W., Otieno, D., Ko, J., Werner, C., and Tenhunen, J.: Conditional variations in temperature response of photosynthesis, mesophyll and stomatal control of water use in rice and winter wheat, Field Crop. Res., 199, 77-88, 2016 c.

Xue, W., Lindner, S., Dubbert, M., Otieno, D., Ko, J., Muraoka, H., Werner, C., and Tenhunen, J.: Supplement understanding of the relative importance of biophysical factors in determination of photosynthetic capacity and photosynthetic productivity in rice ecosystems, Agr. Forest Meteorol., 232, 550-565, 2017.

Yoshida, S.: Fundamentals of rice crop science, International Rice Research Institute, Manila, Philippines, 279 pp., 1981.

Zhang, C. and Kovacs, J. M.: The application of small unmanned aerial systems for precision agriculture: a review, Precis. Agric., 13, 693-712, 2012. 